
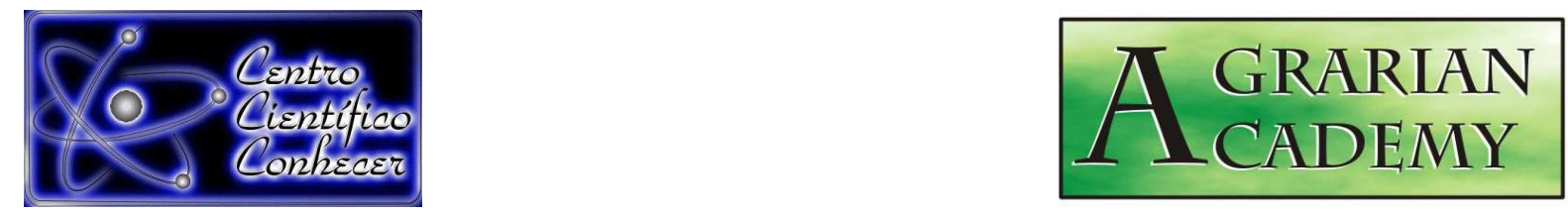

\title{
FAMÍLIA MYRTACEAE: ANÁLISE MORFOLÓGICA E DISTRIBUIÇÃO GEOGRÁFICA DE UMA COLEÇÃO BOTÂNICA
}

Larissa Maria Fernandes Morais'; Gonçalo Mendes da Conceição²; Janilde de Melo Nascimento 3

${ }^{1}$ Graduada em Ciências Biológicas, pela Universidade Estadual do Maranhão/UEMA, Centro de Estudos Superiores de Caxias/CESC, Laboratório de Biologia Vegetal/LABIVE

2Professor Doutor do Centro de Estudos Superiores de Caxias/CESC, Universidade

Estadual do Maranhão/UEMA/Núcleo de Pesquisa dos Cerrados

Maranhenses/RBCEM, Laboratório de Biologia Vegetal/LABIVE

3Mestra em Ciências Biológicas/Botânica Tropical/Universidade Estadual do Maranhão/UEMA, Centro de Estudos Superiores de Caxias/CESC, Laboratório de Biologia Vegetal/LABIVE

Recebido em: 03/01/2014 - Aprovado em: 04/04/2014 - Publicado em: 12/04/2014

\section{RESUMO}

Myrtaceae constitui uma das mais importantes famílias de Angiospermas no Brasil, concentrada em uma única tribo, Myrteae e três subtribos Myrciinae, Eugeniinae e Myrtinae. É considerada uma das famílias mais bem representadas no Brasil, com distribuição de suas espécies em todos os biomas. O estudo objetivou listar as espécies de Myrtaceae de uma coleção botânica, caracterizar morfologicamente e fazer a distribuição geográfica no âmbito do Brasil. O material botânico analisado faz parte da coleção botânica, do Laboratório de Biologia Vegetal/LABIVE. Todo o material herborizado foi analisado, fotografado, seguido da caracterização morfológica e distribuição geográfica para cada espécie. Na coleção registrou-se 100 espécimes, distribuídos em 11 gêneros e 44 espécies. A Coleção Botânica dispõe em seu acervo exemplares do Maranhão e dos Estados do Distrito Federal, Minas Gerais, Bahia, Goiás, Mato Grosso, Sergipe e Rio Grande do Norte. Para o Maranhão foram registrados 64 espécimes e para os demais estados foram contabilizados 36 espécimes. Os gêneros mais representativos da família Myrtaceae foram Eugenia L. com 37 espécimes e Myrcia DC., com 32 espécimes. Das 44 espécies de Myrtaceae caracterizadas, foram registradas 15 novas ocorrências para o Maranhão. A família Myrtaceae tem grande importância econômica, ecológica e medicinal, porém, os estudos são poucos, tendo-se a necessidade de intensificar as pesquisas para ampliar o conhecimento do número de espécies para o Maranhão.

PALAVRAS-CHAVES: Angiospermas, coleção biológica, Diversidade florística 


\title{
FAMILY MYRTACEAE: MORPHOLOGICAL ANALYSIS AND GEOGRAPHICAL DISTRIBUTION OF A BOTANICAL COLLECTION
}

\begin{abstract}
Myrtaceae is one of the most important families of Angiosperms in Brazil, concentrated in a single tribe, and three subtribes Myrteae, Myrciinae, Eugeniinae and Myrtinae. It is considered one of the best represented families in Brazil, with distribution of its species in all biomes. The study aimed to list the species of Myrtaceae from a botanical collection, and to morphologically characterize the geographic distribution within Brazil. The plant material analyzed is part of the Botanical Collection, Laboratory of Plant Biology / LABIVE. All the dried material was analyzed, photographed, followed by morphological characterization and geographic distribution for each species. In the collection was recorded 100 specimens, distributed in 11 genera and 44 species. The Botanical Collection has copies in his collection of states of Maranhão and the Federal District, Minas Gerais, Bahia, Goias, Mato Grosso, Sergipe and Rio Grande do Norte. To Maranhão 64 specimens were recorded and the remaining 36 states were recorded specimens. The most representative genera of the Myrtaceae family were Eugenia L. with 37 specimens and Myrcia DC. With 32 specimens, of the 44 species of Myrtaceae characterized, there were 15 new occurrences to Maranhão. The Myrtaceae family has great economic, ecological and medicinal importance, however, the studies are few, and the need to intensify research to expand knowledge of the number of species to Maranhão.
\end{abstract}

KEYWORDS: Angiosperms, Floristic diversity, Biological collection

\section{INTRODUÇÃO}

Myrtaceae constitui uma das mais importantes famílias de Angiospermas no Brasil, concentrada em uma única tribo, Myrteae e três subtribos Myrciinae, Eugeniinae e Myrtinae (LANDRUM \& KAWASAKI, 1997).

De acordo com SOARES-SILVA (2000) a família Myrtaceae corresponde a $1,32 \%$ do total de angiospermas conhecidas, sendo assim, bastante representativa, considerando um total de 400 famílias.

A família Myrtaceae compreende cerca de 140 gêneros e 3.500 espécies de árvores e arbustos. Estão distribuídas em regiões tropicais e subtropicais da Austrália, Ásia e América (ANGIOSPERM PHYLOGENY GROUP III, 2009). Divididas nas subfamílias: Myrtoideae (com frutos do tipo baga e folhas opostas), distribuída principalmente na América do Sul e Central e Leptospermoideae (com frutos do tipo cápsulas ou núculas e folhas alternas ou opostas), com maior concentração na Austrália. Para o Brasil são registrados 23 gêneros e cerca de 997 espécies (SOBRAL et al., 2014), distribuídas principalmente na Floresta Atlântica, onde são encontradas 636 espécies (SOBRAL et al., 2009). Já para o Maranhão cerca de 60 espécies, distribuídas em 6 gêneros (ARAGÃO \& CONCEIÇÃO, 2007).

É considerada uma das famílias mais bem representadas no Brasil, e compreende diversos tipos de vegetação como: Floresta Ombrófila ou Mata Atlântica de encostas (SOARES-SILVA, 2000; MYERES et al., 2000); Floresta Amazônica (SILVA et al., 2005); Restinga (LOURENÇO \& BARBOSA, 2012) e Cerrado (SILVAFILHO, 2006). Sendo uma das famílias mais citadas em estudos florísticos e fitossociológicos. ARAGÃO \& CONCEIÇÃO (2007) citam que no Maranhão as espécies de Myrtaceae possuem adaptabilidade aos ambientes que vão desde Floresta Tropical úmida até o Cerrado. 
A família Myrtaceae apresenta grande potencial econômico, muitas de suas espécies são utilizadas na alimentação, como, as espécies de Psidium guajava L. da goiaba e Eugenia uniflora L. da "pitanga", consumidas em forma de suco, doces, geleias e sorvetes (LORENZI et al., 2006). Segundo LORENZI \& SOUZA, (2001), na ornamentação, destacam-se as espécies (Eugenia sprengelii DC.), da "murta" e (Leptospermum scoparium J.R.Forst; G.Forst.), da "érica". E como medicinais destacam as (Eucalyptus globulus L.), o "eucalipto", empregado no tratamento da gripe, congestão nasal e sinusite; e (Myrciaria dubia (Kunth) Mc Vaugh), o "camu-camu" que apresenta alto teor de vitamina C, segundo informações etnofarmacológicas (LORENZI \& MATOS, 2002).

Também apresentam importância ecológica, pois seus frutos suculentos e carnosos são fontes de alimento à fauna silvestre. Muitos animais que se alimentam desses frutos acabam veiculando a dispersão das sementes e favorecendo a sobrevivência e permanência dessas espécies (PIZZO 2003; GRESSLER et al., 2006).

No sistema taxonômico, Myrtaceae pertence a um grupo de plantas, cuja divisão é Magnoliophyta, à classe Magnoliopsida e à ordem Myrtales (ANGIOSPERM PHYLOGENY GROUP III, 2009). É uma das famílias mais complexas, do ponto de vista taxonômico, tanto pelo número de espécies e também devido à escassez de estudos taxonômicos (SOUSA \& LORENZI, 2008). E principalmente pelo fato de que a maioria das descrições data de mais de um século, além do uso de caracteres crípticos no diagnóstico genérico e limites poucos conclusivos deste táxon (LANDRUM \& KAWASAKI, 1997).

A descrição de novas espécies para o Brasil tem contribuído para o conhecimento da diversidade da família Myrtaceae no país, porém os estudos não são suficientes na região Nordeste e principalmente no Maranhão. $O$ presente estudo objetivou listar as espécies de Myrtaceae de uma coleção botânica, caracterizar morfologicamente e fazer a distribuição geográfica no âmbito do Brasil.

\section{MATERIAL E MÉTODOS}

O levantamento foi realizado na Coleção Botânica, do Laboratório de Biologia Vegetal do CESC/UEMA, nos meses de setembro de 2013 a janeiro de 2014. Atualmente esta coleção conta com 4.135 exsicatas. Entre essas exsicatas encontram amostras doadas por outros Estados como, São Paulo, Mato Grosso, Mato Grosso do Sul, Goiás, Distrito Federal, entre outros.

Os procedimentos realizados foram divididos em duas etapas. Na primeira etapa, as amostras foram separadas em exsicatas identificadas e exsicatas não identificadas. As exsicatas identificadas foram fotografadas e catalogadas em táxon genérico e especifico, citando o nome do coletor, local e ambiente de ocorrência.

$\mathrm{Na}$ segunda etapa, os dados coletados foram colocados em planilha do Programa Excel para armazenamento das informações e comparados com dados da literatura para obtenção de referencial teórico, em seguida fez-se a caracterização das espécies.

\section{RESULTADOS E DISCUSSÃO}

A Coleção Botânica do Laboratório de Biologia Vegetal, no que concerne a família Myrtaceae, apresenta até o momento 100 espécimes, distribuídos 11 gêneros e 44 espécies (tab. 01). 
TABELA 1 - Lista de espécies, gêneros e número de espécimes da família Myrtaceae mantida sob coleção, no Laboratório de Biologia Vegetal/LABIVE, do Centro de Estudos Superiores de Caxias/CESC, da Universidade Estadual do Maranhão.

\begin{tabular}{|c|c|c|}
\hline Gêneros & Espécies & № de espécimes \\
\hline \multirow[t]{15}{*}{ Eugenia L. } & Eugenia sp. & 10 \\
\hline & Eugenia bracteata Vell. (Fig. A) & 02 \\
\hline & Eugenia punicifolia (Kunth) DC. (Fig.B) & 09 \\
\hline & Eugenia uniflora L. & 03 \\
\hline & Eugenia dysenterica (Mart.) DC. & 03 \\
\hline & Eugenia uruguayensis Cambess. & 01 \\
\hline & Eugenia klotzschina O. Berg & 01 \\
\hline & Eugenia speciosa Cambess. & 01 \\
\hline & Eugenia subterminalis DC. & 02 \\
\hline & Eugenia dimorpha O. Berg & 01 \\
\hline & Eugenia stenosepala Kiaersk. (Fig.C) & 01 \\
\hline & Eugenia involucrata DC. & 01 \\
\hline & Eugenia persicifolia (O. Berg) Mattos & 01 \\
\hline & Eugenia ayacuchae Steyerm. & 01 \\
\hline & Eugenia flavescens DC. & 01 \\
\hline \multirow[t]{14}{*}{ Myrcia DC. } & Myrcia sp. & 12 \\
\hline & Myrcia guianensis (Aubl.) DC. & 02 \\
\hline & Myrcia multiflora (Lam.) DC. & 01 \\
\hline & Myrcia sellowiana O. Berg (Fig. D) & 02 \\
\hline & Myrcia cordiifolia DC. & 01 \\
\hline & Myrcia rostrata DC. & 04 \\
\hline & Myrcia torta DC. (Fig. E) & 01 \\
\hline & Myrcia tomentosa (Aubl.) DC. & 03 \\
\hline & Myrcia rorida (O. Berg) Kiaersk. & 01 \\
\hline & Myrcia rufipes DC. & 01 \\
\hline & Myrcia lancea Berg & 01 \\
\hline & Myrcia canescens O. Berg (Fig.F) & 01 \\
\hline & Myrcia goyazensis Cambess. & 01 \\
\hline & Myrcia ocroides O. Berg & 01 \\
\hline \multirow[t]{7}{*}{ Psidium L. } & Psidium sp. & 02 \\
\hline & Psidium rufum Mart. ex DC. & 01 \\
\hline & Psidium guajava L. & 01 \\
\hline & Psidium myrsinoides O. Berg & 04 \\
\hline & Psidium pohlianum Berg & 02 \\
\hline & Psidium megalianum Cambess. & 01 \\
\hline & Psidium nutans O. Berg & 01 \\
\hline \multirow{3}{*}{$\begin{array}{l}\text { Campomanesia } \\
\text { Ruiz \& Pav. }\end{array}$} & Campomanesia sp. & 01 \\
\hline & $\begin{array}{l}\text { Campomanesia xanthocarpa (Mart.) O. } \\
\text { Berg }\end{array}$ & 03 \\
\hline & $\begin{array}{l}\text { Campomanesia velutina (Cambess.) } \\
\text { O.Berg }\end{array}$ & 01 \\
\hline
\end{tabular}




\begin{tabular}{|c|c|c|}
\hline & $\begin{array}{l}\text { Campomanesia pubescens (Mart. ex } \\
\text { DC.) O. Berg }\end{array}$ & 01 \\
\hline & $\begin{array}{l}\text { Campomanesia sessiliflora (O. Berg) } \\
\text { Mattos }\end{array}$ & 01 \\
\hline \multirow[t]{2}{*}{ Myrciaria O.Berg } & Myrciaria sp. & 01 \\
\hline & Myrciaria tenella (DC.) O. Berg & 02 \\
\hline \multirow[t]{2}{*}{ Gomidesia O.Berg } & Gomidesia sp. & 01 \\
\hline & Gomidesia lindeniana Berg & 01 \\
\hline $\begin{array}{l}\text { Blepharocalyx O. } \\
\text { Berg }\end{array}$ & $\begin{array}{l}\text { Blepharocalyx salicifolius (kunth) O. } \\
\text { Berg (Fig. G) }\end{array}$ & 02 \\
\hline $\begin{array}{l}\text { Myrceugenia } \\
\text { O.Berg }\end{array}$ & Myrceugenia cucullata D. Legrand & 01 \\
\hline $\begin{array}{l}\text { Marlierea } \\
\text { Cambess. }\end{array}$ & $\begin{array}{l}\text { Marlierea bipennis (O. Berg) Mc Vaugh } \\
\text { (Fig.H) }\end{array}$ & 01 \\
\hline $\begin{array}{l}\text { Calycorectes } \mathrm{O} . \\
\text { Berg }\end{array}$ & $\begin{array}{l}\text { Calycorectes psidiiflorus (O. Berg) } \\
\text { Sobral }\end{array}$ & 01 \\
\hline $\begin{array}{l}\text { Siphoneugena } \mathrm{O} . \\
\text { Berg }\end{array}$ & Siphoneugena densiflora O. Berg & 01 \\
\hline
\end{tabular}

O gênero Eugenia apresentou maior frequência na Coleção Botânica, sendo 37 exemplares (37\%), seguidos de Myrcia com 32 (32\%), Psidium com 12 (12\%), Campomanesia com oito (8\%), Myrciaria com três (3\%), Gomidesia com dois $(2 \%)$, Blepharocalyx com dois (2\%), Siphoneugena com um (1\%), Calycorectes com um (1\%), Marlierea com um (1\%), e Myrceugenia com um (1\%) de exemplar (Fig. 01).

Quanto ao número de espécies, Eugenia obteve 14 espécies diferentes, Myrcia com 13, Psidium com seis, Campomanesia com quatro, Blepharocalyx com uma, Myrciaria com uma, Gomidesia com uma, Siphoneugena com uma, Calycorectes com um, Marlierea com uma, e Myrceugenia com uma espécie (Fig. $02)$.

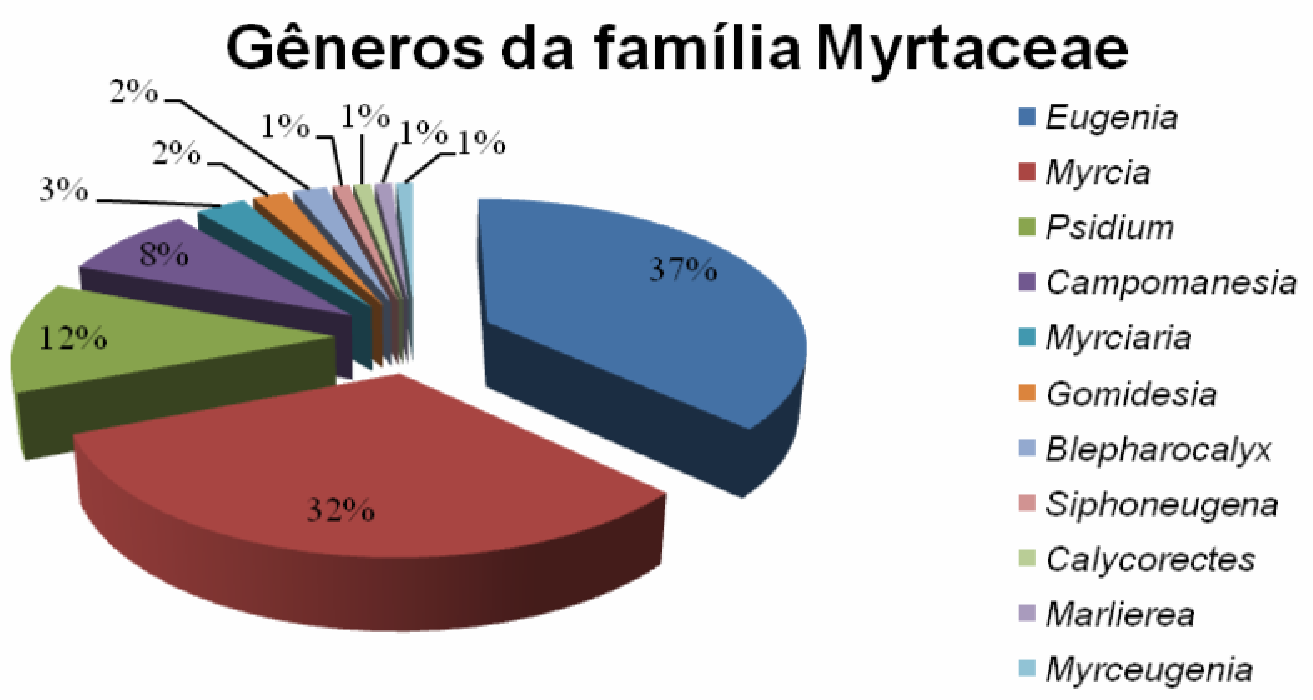

FIGURA 1 - Frequência de gêneros da família Myrtaceae da Coleção Botânica do Laboratório de Biologia Vegetal do CESC/UEMA. 


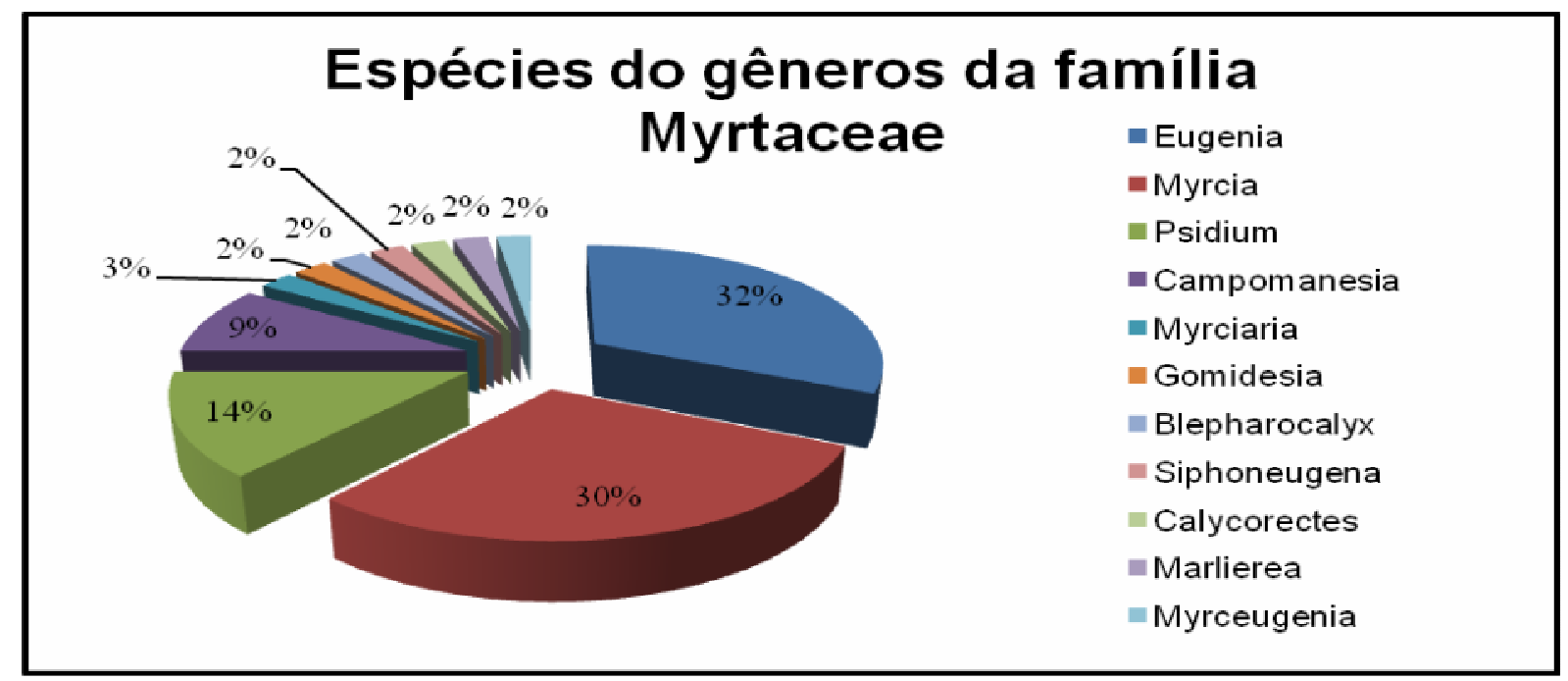

FIGURA 2 - Frequência de espécies dos gêneros da família Myrtaceae da Coleção Botânica do Laboratório de Biologia Vegetal do CESC/UEMA.

O gênero Eugenia L. constitui um dos maiores gêneros da família Myrtaceae, apresentando cerca de 1.115 espécies, distribuídas, principalmente, nas regiões tropicais das Américas. Grande parte de suas espécies são usadas na medicina popular e muitas submetidas a estudos químicos e avaliações de ações farmacológicas (DIAS et al., 2012).

Eugenia punicifolia (Kunth) DC., foi a espécie do gênero que apresentou um padrão de distribuição mais amplo em relação as demais, sendo encontrada em 25 Estados do Brasil, de acordo com a lista de espécies da Flora do Brasil (2014).

Os dados coletados registram que os espécimes de Myrtaceae acervados na Coleção Botânica compõem a flora Maranhense dos municípios de Caxias, Mirador e Balsas. Alguns espécimes foram doados, enviados de outras regiões do Brasil, como os Estados do Distrito Federal, Minas Gerais, Bahia, Goiás, Mato Grosso do Sul, Sergipe e Rio Grande do Norte.

No Maranhão, dos espécimes listados, 34 foram registradas para o município de Caxias, sendo 30 para Área de Proteção Ambiental Municipal do Inhamum, um na comunidade quilombola Olho D'água do Raposo, um na Fazenda Nova e dois no Morro do Alecrim. No município de Mirador foram registradas 25 espécimes para o Parque Estadual do Mirador. Cinco para o Projeto Geral de Balsas lote 16 (área recém-queimada), município de Balsas, totalizando 64 espécimes da família Myrtaceae listadas na Coleção Botânica para Estado do Maranhão (Tab. 02).

TABELA 2 - Lista de espécimes da família Myrtaceae ocorrentes nos municípios de Caxias, Mirador e Balsas acervadas sob coleção botânica.

\begin{tabular}{|c|c|c|}
\hline Municípios & Locais & Espécimes \\
\hline \multirow[t]{7}{*}{ Caxias } & \multirow{7}{*}{$\begin{array}{l}\text { APA do Inhamum } \\
\text { /Comunidade quilombola } \\
\text { Olho D’água do Raposo/ } \\
\text { Fazenda Nova/ Morro do } \\
\text { Alecrim }\end{array}$} & Eugenia sp. (10) \\
\hline & & Myrcia sp. (06) \\
\hline & & Campomanesia sp.(01) \\
\hline & & Eugenia uniflora L. (03) \\
\hline & & Myrceugenia cucullata D. Legrand (01) \\
\hline & & Eugenia speciosa Cambess. (01) \\
\hline & & Myrcia guianensis (Aubl.) DC. (02) \\
\hline Caxias & Inhamum & $\begin{array}{l}\text { Campomanesia xanthocarpa (Mart.) O. } \\
\text { Berg (02) }\end{array}$ \\
\hline
\end{tabular}




\begin{tabular}{|c|c|c|}
\hline & \multirow{6}{*}{$\begin{array}{l}\text { /Comunidade quilombola } \\
\text { Olho D’água do Raposo/ } \\
\text { Fazenda Nova/ Morro do } \\
\text { Alecrim }\end{array}$} & Eugenia subterminalis DC. (02) \\
\hline & & Myrciaria tenella (DC.) O. Berg (02) \\
\hline & & Myrcia multiflora (Lam.) DC. (01) \\
\hline & & Eugenia punicifolia (Kunth) DC. (01) \\
\hline & & Eugenia dimorpha O. Berg (01) \\
\hline & & Psidium guajava L. (01) \\
\hline \multirow[t]{15}{*}{ Mirador } & \multirow{15}{*}{$\begin{array}{l}\text { Parque Estadual do } \\
\text { Mirador }\end{array}$} & Myrcia sp.(01) \\
\hline & & Eugenia dysenterica (Mart.) DC. (03) \\
\hline & & Psidium pohlianum Berg (02) \\
\hline & & Myrcia rostrata DC. (03) \\
\hline & & Eugenia punicifolia (Kunth) DC. (05) \\
\hline & & $\begin{array}{l}\text { Eugenia persicifolia (O. Berg) Mattos } \\
(01)\end{array}$ \\
\hline & & Eugenia ayacuchae Steyerm. (01) \\
\hline & & Myrcia rufipes DC. (01) \\
\hline & & Myrcia lancea Berg (01) \\
\hline & & Myrcia tomentosa (Aubl.) DC. (02) \\
\hline & & Myrcia canescens O. Berg (01) \\
\hline & & Psidium megalianum Cambess. (01) \\
\hline & & Psidium nutans O. Berg (01) \\
\hline & & $\begin{array}{l}\text { Campomanesia xanthocarpa (Mart.) O. } \\
\text { Berg (01) }\end{array}$ \\
\hline & & Eugenia flavescens DC. (01) \\
\hline \multirow[t]{4}{*}{ Balsas } & \multirow{4}{*}{$\begin{array}{l}\text { Projeto geral de Balsas } \\
\text { (área recém-queimada) }\end{array}$} & Myrcia sp. (01) \\
\hline & & Eugenia punicifolia (Kunth) DC. (01) \\
\hline & & Psidium myrsinoides O. Berg (02) \\
\hline & & Myrcia ochroides O. Berg (01) \\
\hline
\end{tabular}

O número reduzido de espécies da família Myrtaceae para o Estado do Maranhão em relação ao Cerrado Brasileiro, se deve provavelmente pela escassez de trabalhos científicos, não sendo indícios de baixa diversidade de espécies (ARAGÃO \& CONCEIÇÃO, 2007). Estudos realizados por esses pesquisadores, sobre as Myrtaceae do Maranhão, relatam 60 espécies distribuídas em 6 gêneros. 0 presente estudo vem complementar e registrar para o Maranhão, novas ocorrências de espécies dentro desta família, a saber, Eugenia subterminalis, Eugenia speciosa, Eugenia uniflora e Myrceugenia cucullata, ocorrentes no município de Caxias (SOUSA, 2011).

No Distrito Federal foram registrados 20 espécimes para os referidos municípios: Brasília, Brazlândia e Palmeiras. Em Minas Gerais, foram registrados seis espécimes, nos município de Garapuava, entre São Francisco e São Romão, Umuarama e São Romão.

Para o estado da Bahia registrou-se quatro espécimes, nos municípios de Rio de Contas, Correntina. Em Goiás, registraram-se três espécimes nos municípios de Cristalina e Alto Paraíso de Goiás.

No Mato Grosso do Sul, foi registrado um espécime entre os municípios de Aquiduana e Campo Grande. Sergipe, um espécime no município de Maraú. Rio de Grande do Norte, um espécime no município de Goianinha. 
Para os Estados citados acima foram contabilizados 36 espécimes para a família Myrtaceae listadas na Coleção Botânica do Laboratório de Biologia Vegetal do CESC/UEMA (Tab. 3).

TABELA 3 - Lista de espécimes da família Myrtaceae para os estados do DF, MS, MG, BA, GO, SE, RN, acervadas na Coleção Botânica do LABIVE.

\begin{tabular}{|c|c|c|}
\hline Estado & Cidade & Espécimes \\
\hline \multirow[t]{17}{*}{ Distrito Federal } & \multirow{17}{*}{$\begin{array}{l}\text { Brasília/ } \\
\text { Brazlândia/ } \\
\text { Palmeiras }\end{array}$} & Eugenia bracteata Vell. (02) \\
\hline & & Siphoneugena densiflora O. Berg (01) \\
\hline & & Psidium sp. (01) \\
\hline & & Marlierea bipennis (O. Berg) Mc Vaugh (01) \\
\hline & & Eugenia klotzschina O. Berg (01) \\
\hline & & Eugenia stenosepala Kiaersk. (01) \\
\hline & & Psidium myrsinoides O. Berg (02) \\
\hline & & Myrcia sellowiana O. Berg (02) \\
\hline & & Myrcia cordiifolia DC. (01) \\
\hline & & $\begin{array}{l}\text { Campomanesia pubescens (Mart. ex DC.) O. } \\
\text { Berg (01) }\end{array}$ \\
\hline & & $\begin{array}{l}\text { Campomanesia velutina (Cambess.) O. Berg } \\
(01)\end{array}$ \\
\hline & & Gomidesia lindeniana Berg (01) \\
\hline & & Myrcia rostrata DC. (01) \\
\hline & & Myrcia torta DC. (01) \\
\hline & & Eugenia involucrata DC. (01) \\
\hline & & Myrciaria sp. (01) \\
\hline & & Myrcia sp. (01) \\
\hline $\begin{array}{l}\text { Mato Grosso do } \\
\text { Sul }\end{array}$ & $\begin{array}{l}\text { Entre } \\
\text { Arquiduana e } \\
\text { Campo Grande } \\
\end{array}$ & Myrcia sp.(01) \\
\hline \multirow[t]{6}{*}{ Minas Gerais } & \multirow{6}{*}{$\begin{array}{l}\text { Entre São } \\
\text { Francisco e São } \\
\text { Romão/ } \\
\text { Umuarama/ } \\
\text { Garapuava/ } \\
\text { São Romão }\end{array}$} & $\begin{array}{l}\text { Calycorectes psidiiflorus (O. Berg) Sobral } \\
(01)\end{array}$ \\
\hline & & Myrcia sp. (01) \\
\hline & & $\begin{array}{l}\text { Campomanesia sessiliflora (O. Berg) Mattos } \\
(01)\end{array}$ \\
\hline & & Myrcia tomentosa (Aubl.) DC. (01) \\
\hline & & Myrcia rorida (O. Berg) Kiaersk (01) \\
\hline & & Myrcia goyazensis Cambess. (01) \\
\hline \multirow[t]{3}{*}{ Bahia } & \multirow{3}{*}{$\begin{array}{l}\text { Rio de Contas/ } \\
\text { Correntina }\end{array}$} & Psidium rufum Mart. ex DC. (01) \\
\hline & & Blepharocalyx salicifolius (kunth) O. Berg (02) \\
\hline & & Myrcia sp. (01) \\
\hline \multirow[t]{3}{*}{ Goiás } & \multirow{3}{*}{$\begin{array}{l}\text { Cristalina/ } \\
\text { Alto Paraíso do } \\
\text { Goiás }\end{array}$} & Eugenia punicifolia (Kunth) DC. (01) \\
\hline & & Eugenia uruguayensis Cambess. (01) \\
\hline & & Gomidesia sp. (01) \\
\hline Sergipe & Maraú & Psidium sp. (01) \\
\hline $\begin{array}{l}\text { Rio Grande do } \\
\text { Norte }\end{array}$ & Goianinha & Eugenia punicifolia (Kunth) DC. (01) \\
\hline
\end{tabular}




\section{CARACTERIZAÇÃO BOTÂNICA E DISTRIBUIÇÃO GEOGRÁFICA DAS ESPÉCIES DE MYRTACEAE MANTIDA SOB COLEÇÃO BOTÂNICA}

Eugenia bracteata Vell. FI. Flumin. 5: 209, t. 40. 1829.

Nome vulgar: Cerejeira-do-mato.

Arbusto $1 \mathrm{~m}$, folhas simples, 4-7, $2 \mathrm{~cm}$ de comp. $\times$ 2,2-2,9 cm de larg., bicolor, lanceolada, base cuneada, ápice agudo, margem inteira, nervura primária e secundária proeminente em ambas as faces, face abaxial e adaxial glabra. Fruto do tipo baga com $0,8 \mathrm{~cm}$ de diâmetro, imaturo, cálice persistente com 4 lobos. Esta espécie, de acordo com a Flora do Brasil é registro novo para o Distrito Federal.

Material examinado: Brasil, Distrito Federal, Parque Nacional de Brasília, fértil, 26/X/1990. Ramos, P.C.M. 222. Jardim Botânico de Brasília, fértil, 16/X/2001. Soares e Silva, L.H. 1126.

Distribuição geográfica: Sudeste (Espírito Santo, Minas Gerais, Rio de Janeiro, São Paulo), Sul (Paraná, Rio Grande do Sul, Santa Catarina).

Domínios fitogeográficos: Cerrado, Mata Atlântica.

Campomanesia velutina (Cambess.) O.Berg Linnaea 27(4): 429. 1856.

Nome vulgar: Gabiroba.

Árvore $5 \mathrm{~m}$, folhas simples, $5-7 \mathrm{~cm}$ de comp. $\times 2,2-3 \mathrm{~cm}$ de larg., bicolor, lanceolada, base cuneada, ápice acuminado, margem inteira, nervura primária e secundária proeminente em ambas as faces, face abaxial com endurecimento do tipo velutino e adaxial glabra. Fruto do tipo baga com $0,6 \mathrm{~cm}$ de diâmetro, imaturo, com endurecimento do tipo pubescente, cálice persistente com 5 lobos.

Material examinado: Brasil, Distrito Federal, Brasília, 15/X/2001. JESUS, et al. 130. Distribuição geográfica: Norte (Tocantins), Nordeste (Bahia, Ceará, Maranhão, Piauí, Rio Grande do Norte), Centro-oeste (Distrito Federal, Goiás, Mato Grosso do Sul), Sudeste (Minas Gerais, São Paulo).

Domínios fitogeográficos: Caatinga, Cerrado, Mata Atlântica.

Eugenia subterminalis DC. Prodr. 3: 263. 1828.

Nome vulgar: Guamirim.

Arbusto, folhas simples, 2,6-5,5 $\mathrm{cm}$ de comp. $\times 1,1-2,4 \mathrm{~cm}$ de larg., bicolor, lanceolada, base cuneada, ápice acuminado, margem inteira, nervura primária e secundária proeminente em ambas as faces, face abaxial glabra e adaxial com endurecimento do tipo piloso. Fruto do tipo baga com $0,3 \mathrm{~cm}$ de diâmetro, imaturo, com endurecimento do tipo piloso, cálice persistente com 4 lobos. Esta espécie, de acordo com a Flora do Brasil é registro novo para o Maranhão.

Material examinado: Brasil, Maranhão, Caxias, APA do Inhamum, fértil. Conceição, G.M.

Distribuição geográfica: Norte (Amazonas), Nordeste (Bahia), Centro-oeste (Mato Grosso do Sul), Sudeste (Espírito Santo, Minas Gerais, Rio de Janeiro, São Paulo), Sul (Paraná, Rio Grande do Sul, Santa Catarina).

Domínios fitogeográficos: Amazônia, Caatinga, Mata Atlântica, Cerrado.

Myrcia guianensis (Aubl.) DC. Prodr. 3: 245. 1828.

Nome vulgar: Guamirim.

Arbusto, Folhas simples, $1,2-5,4 \mathrm{~cm}$ de comp. $\times$ 0,9-2,5 $\mathrm{cm}$ de larg., bicolor, lanceolada, base cuneada, ápice agudo, margem inteira, nervura primária e secundária proeminente em ambas as faces. Face adaxial e abaxial glabra. Fruto do 
tipo baga com $0,5 \mathrm{~cm}$ de diâmetro, imaturo, cálice persistente com 5 lobos. Esta espécie, de acordo com a Flora do Brasil é registro novo para o Maranhão.

Material examinado: Brasil, Maranhão, Caxias, APA do Inhamum, fértil. Conceição, G.M.

Distribuição geográfica: Norte (Acre, Amazonas, Amapá, Pará), Nordeste (Alagoas, Bahia, Ceará, Pernambuco, Rio Grande do Norte), Centrooeste (Goiás, Mato Grosso do Sul, Mato Grosso), Sudeste (Espírito Santo, Minas Gerais, Rio de Janeiro, São Paulo), Sul (Rio Grande do Sul, Santa Catarina).

Domínios fitogeográficos: Amazônia, Caatinga, Cerrado, Mata Atlântica.

Eugenia flavescens DC. Prodr. 3: 272. 1828.

Nome vulgar: Araçá da mata.

Arbusto $1,50 \mathrm{~m}$, folhas simples, 1,9-5,1 cm de comp. x 0,7-2 cm de larg., bicolor, lanceolada, base cuneada, ápice agudo, margem inteira, nervura primária e secundária proeminente em ambas as faces, face abaxial e adaxial glabra. Fruto do tipo baga com 0,4 cm de diâmetro, imaturo, cálice persistente com 4 lobos.

Material examinado: Brasil, Maranhão, Parque Estadual do Mirador, fértil, 07/XI/1998. Conceição, G.M. 374.

Distribuição geográfica: Norte (Acre, Amazonas, Amapá, Pará, Rondônia, Roraima, Tocantins), Nordeste (Bahia, Ceará, Maranhão, Pernambuco, Piauí, Rio Grande do Norte), Centro-oeste (Goiás, Mato Grosso do Sul, Mato Grosso), Sudeste (Espírito Santo, Minas Gerais, São Paulo).

Domínios fitogeográficos: Amazônia, Caatinga, Cerrado, Mata Atlântica.

Campomanesia xanthocarpa (Mart.) O. Berg FI. Bras. 14(1): 451. 1857.

Nome vulgar: Guabiroba.

Árvore $3 \mathrm{~m}$, folhas simples, 5-8, $9 \mathrm{~cm}$ de comp. x 1,8-3,8 cm de larg., bicolor, oblongo-lanceolada, base obtusa, ápice obtuso, margem inteira, nervura primária e secundária proeminente em ambas as faces, face abaxial e adaxial glabra. Ausência de Fruto. Inflorescência dicásio. Esta espécie, de acordo com a Flora do Brasil é registro novo para o Maranhão.

Material examinado: Brasil, Maranhão, Parque Estadual do Mirador, fértil, 08/XI/1998. Conceição, G.M. 391. Maranhão, Caxias, APA do Inhamum, fértil, 18/XII/2006. Rodrigues; Conceição, G.M. 534.

Distribuição geográfica: Nordeste (Bahia), Centro-oeste (Distrito Federal, Goiás, Mato Grosso do Sul), Sudeste (Espírito Santo, Minas Gerais, Rio de Janeiro, São Paulo), Sul (Paraná, Rio Grande do Sul, Santa Catarina).

Domínios fitogeográficos: Cerrado, Mata Atlântica.

Eugenia speciosa Cambess. FI. Bras. Merid. (quarto ed.) 2: 351. 1832.

Nome vulgar: Laranjinha-do-mato.

Arbusto, folhas simples, 7,5-9,6 cm de comp. $x$ 3,3-4,1 cm de larg., bicolor, lanceolada, base cuneada, ápice agudo, margem inteira, nervura primária e secundária proeminente em ambas as faces, face abaxial glabra e adaxial com endurecimento do tipo barbado. Fruto do tipo baga com 1,7 cm de diâmetro, imaturo, cálice persistente com 4 lobos. Esta espécie, de acordo com a Flora do Brasil é registro novo para o Maranhão.

Material examinado: Brasil, Maranhão, APA do Inhamum, fértil. Conceição, G. M. Distribuição geográfica: Sudeste (Minas Gerais, Rio de Janeiro, São Paulo) Sul (Paraná, Rio Grande do Sul, Santa Catarina). 
Domínios fitogeográficos: Mata Atlântica.

Eugenia klotzschina O. Berg FI. Bras. 14(1): 255. 1859.

Nome vulgar: Pera-do-campo.

Subarbusto heliófilo 1,50 m, folhas simples, 1,9-5,1 cm de comp. x 0,7-2 cm de larg., bicolor, lanceolada, base cuneada, ápice obtuso, margem inteira, nervura primária $e$ secundária proeminente em ambas as faces, face abaxial com endurecimento piloso e adaxial glabra. Inflorescência racemo com endurecimento pubescente. Esta espécie, de acordo com a Flora do Brasil é registro novo para o Distrito Federal.

Material examinado: Brasil, Distrito Federal. APA do Gama, fértil, 09/IX/2002. Mendonça, R. C.; Alvarenga, D. 4971.

Distribuição geográfica: Nordeste (Bahia), Centro-oeste (Goiás, Mato Grosso do Sul), Sudeste (Minas Gerais, São Paulo).

Domínios fitogeográficos: Cerrado, Mata Atlântica.

Eugenia uruguayensis Cambess. FI. Bras. Merid. (quarto ed.) 2: 362. 1833.

Nome vulgar: Batinga-vermelha.

Árvore 2,5 m, folhas simples, 3-5, $5 \mathrm{~cm}$ de comp. x 1,5-2,5 cm de larg., bicolor, lanceolada, base cuneada, ápice agudo, margem inteira, nervura primária e secundária proeminente em ambas as faces. Face adaxial com endurecimento do tipo piloso e abaxial glabra. Inflorescência em botões, tipo umbela. Fruto ausente. Esta espécie, de acordo com a Flora do Brasil é registro novo para Goiás.

Material examinado: Brasil, Goiás, Alto Paraíso de Goiás, fértil, 05/XII/2004. Chaves, E.; Soares e Silva, L. H. 134.

Distribuição geográfica: Sul (Paraná, Rio Grande do Sul, Santa Catarina). Domínios fitogeográficos: Mata Atlântica.

Myrceugenia cucullata D. Legrand. Darwiniana 11: 347, f. 15, 31C. 1957.

Nome vulgar: Guamirim.

Arbusto, folhas simples, 2,3-5,3 cm de comp. $\times$ 0,9-2,4 cm de larg., bicolor, lanceolada, base cuneada, ápice acuminado, margem inteira, nervura primária e secundária proeminente em ambas as faces, face abaxial e adaxial glabra. Fruto do tipo baga com $0,4 \mathrm{~cm}$ de diâmetro, imaturo, cálice persistente truncado. Esta espécie, de acordo com a Flora do Brasil é registro novo para o Maranhão.

Material examinado: Brasil, Maranhão, APA do Inhamum, fértil. Conceição, G. M.

Distribuição geográfica: Sudeste (Rio de Janeiro, São Paulo), Sul (Paraná, Rio Grande do Sul, Santa Catarina).

Domínios fitogeográficos: Mata Atlântica, Cerrado.

Eugenia uniflora L. FI. Bras. 14(1): 215. 1857.

Nome vulgar: Pitanga.

Arbusto, folhas simples, $1,5-4,5 \mathrm{~cm}$ de comp. x 1-2,2 cm de larg., bicolor, oblongolanceolada, base obtusa, ápice acuminado, margem inteira, nervura primária e secundária proeminente em ambas as faces, face abaxial e adaxial glabra. Fruto do tipo baga com $0,3 \mathrm{~cm}$ de diâmetro, imaturo, cálice persistente com 4 lobos. Esta espécie, de acordo com a Flora do Brasil é registro novo para o Maranhão.

Material examinado: Brasil, Maranhão, Caxias, fértil, 20/XI/2006. Lima, J. R. Caxias, Fazenda Nova, fértil, 01/X/2006.

Distribuição geográfica: Nordeste (Bahia), Sudeste (Espírito Santo, Minas Gerais, Rio de Janeiro, São Paulo), Sul (Paraná, Rio Grande do Sul, Santa Catarina). 
Domínios fitogeográficos: Cerrado, Mata Atlântica, Pampa.

Marlierea bipennis (O. Berg) Mc Vaugh. Mem. New York Bot. Gard. 10: 79. 1958.

Árvore $4 \mathrm{~m}$, folhas simples, $16,5-18 \mathrm{~cm}$ de comp. $\times$ 4-5 $\mathrm{cm}$ de larg., bicolor, lanceolada, base cuneada, ápice agudo, margem inteira, nervura primária e secundária proeminente em ambas as faces, face abaxial com endurecimento do tipo piloso e adaxial glabra. Inflorescência dicásio, fruto do tipo baga com $0,3 \mathrm{~cm}$ de diâmetro, imaturo, cálice persistente truncado. Esta espécie, de acordo com a Flora do Brasil é registro novo para o Distrito Federal.

Material examinado: Brasil, Distrito Federal, Jardim Botânico de Brasília, fértil, 17/X/2001. Soares e Silva, L. H. e Cardoso, C. 1148.

Distribuição geográfica: Norte (Acre, Amazonas, Pará),

Domínios fitogeográficos: Amazônia.

Eugenia punicifolia (Kunth) DC. Prodr. 3: 267. 1828.

Nome vulgar: Cereja-do-cerrado.

Arbusto $1,50 \mathrm{~m}$, folhas simples, $1,3-4,3 \mathrm{~cm}$ de comp. $\times 2,4-2,2 \mathrm{~cm}$ de larg., bicolor, lanceolada, base cuneada, ápice agudo, margem inteira, nervura primária e secundária proeminente em ambas as faces, face abaxial e adaxial com endurecimento do tipo piloso. Fruto do tipo baga com 0,3 cm de diâmetro, imaturo, cálice persistente com 4 lobos.

Material examinado: Brasil, Maranhão, Parque Estadual do Mirador, fértil, 18/IV/1998, 19/IV/1998. Conceição, G. M. 122. Rio Grande do Norte, Goianinha, fértil, 14/VIII/1990. Elias de Paula, J. 3321. Goiás, Cristalina, fértil, 10/VI/2002. Fonseca, M. L. et al. 3411.

Distribuição geográfica: Norte (Acre, Amazonas, Amapá, Pará, Rondônia, Roraima, Tocantins), Nordeste (Alagoas, Bahia, Ceará, Maranhão, Paraíba, Pernambuco, Piauí, Rio Grande do Norte, Sergipe), Centro-oeste (Distrito Federal, Goiás, Mato Grosso do Sul, Mato Grosso), Sudeste (Espírito Santo, Minas Gerais, Rio de Janeiro, São Paulo), Sul (Paraná).

Domínios fitogeográficos: Amazônia, Caatinga, Cerrado, Mata Atlântica.

Blepharocalyx salicifolius (Kunth) O. Berg Linnaea 27(4): 413-414. 1856.

Nome vulgar: Murta.

Arbusto ramificado $2 \mathrm{~m}$, folhas simples, $1-4 \mathrm{~cm}$ de comp. $\times 1-1,5 \mathrm{~cm}$ de larg., bicolor, lanceolada, base cuneada, ápice agudo, margem inteira, nervura primária e secundária proeminente em ambas as faces, face abaxial e adaxial com endurecimento do tipo piloso. Fruto do tipo baga com 0,8 cm de diâmetro, imaturo, com endurecimento do tipo piloso, cálice persistente truncado.

Material examinado: Brasil, Bahia, Pico das Almas, fértil, 11/XII/1988. Harley, R. M. Distribuição geográfica: Nordeste (Bahia), Centro-oeste (Distrito Federal, Goiás, Mato Grosso do Sul, Mato Grosso), Sudeste (Espírito Santo, Minas Gerais, Rio de Janeiro, São Paulo), Sul (Paraná, Rio Grande do Sul, Santa Catarina).

Domínios fitogeográficos: Caatinga, Cerrado, Mata Atlântica, Pampa.

Calycorectes psidiiflorus (O. Berg) Sobral Candollea 40(2): 636. 1985.

Nome vulgar: Cambuí.

Arvoreta 1,8 m, folhas simples, $6-13 \mathrm{~cm}$ de comp. $\times$ 6,5-8 $\mathrm{cm}$ de larg., bicolor, oblongo-lanceolada, base arredondada, ápice arredondado, margem inteira, nervura primária e secundária proeminente em ambas as faces, face abaxial com 
endurecimento do tipo pubescente e adaxial glabra. Inflorescência panícula, ausência de fruto.

Material examinado: Brasil, Minas Gerais, Guarapuava, fértil, 26/XI/2000. Milhomens, L. C. et al. 22.

Distribuição geográfica: Norte (Amazonas), Nordeste (Bahia), Centro-oeste (Mato Grosso do Sul), Sudeste (Espírito Santo, Minas Gerais, Rio de Janeiro, São Paulo), Sul (Paraná, Rio Grande do Sul, Santa Catarina).

Domínios fitogeográficos: Amazônia, Caatinga, Mata Atlântica.

Psidium rufum Mart. ex DC. Prodr. 3: 234. 1828.

Nome vulgar: Araçá-perinha.

Arbusto, folhas simples, 2,8-4 cm de comp. x 1,2-1,5 cm de larg., bicolor, lanceolada, base cuneada, ápice agudo, margem inteira, nervura primária e secundária proeminente em ambas as faces, face abaxial e adaxial com endurecimento do tipo pubescente. Inflorescência racemo, fruto ausente.

Material examinado: Brasil, Bahia, Pico das Almas, fértil, 29/XI/1988. Harley, M. R. Distribuição geográfica: Nordeste (Bahia, Ceará), Centro-oeste (Distrito Federal, Goiás), Sudeste (Espírito Santo, Minas Gerais, Rio de Janeiro, São Paulo), Sul (Paraná).

Domínios fitogeográficos: Cerrado, Mata Atlântica.

Siphoneugena densiflora O. Berg FI. Bras. 14(1): 379. 1857.

Nome vulgar: Maria-preta.

Árvore $4 \mathrm{~m}$, folhas simples, $8-10,5 \mathrm{~cm}$ de comp. $\times 3-4 \mathrm{~cm}$ de larg., bicolor, lanceolada, base cuneada, ápice acuminado, margem inteira, nervura primária e secundária proeminente em ambas as faces, face abaxial e adaxial glabra. Inflorescência em racemo.

Material examinado: Brasil, Distrito Federal, Brazlândia, fértil, 31/VII/1990. Melo, E.; França, F. 359.

Distribuição geográfica: Norte (Amazonas, Pará), Centro-oeste (Distrito Federal, Goiás, Mato Grosso), Sudeste (Espírito Santo, Minas Gerais, Rio de Janeiro, São Paulo), Sul (Paraná, Rio Grande do Sul, Santa Catarina).

Domínios fitogeográficos: Amazônia, Caatinga, Cerrado, Mata Atlântica.

Campomanesia pubescens (Mart. ex DC.) O. Berg Linnaea 27(4): 429. 1856.

Nome vulgar: Gabiroba.

Subarbusto $30 \mathrm{~cm}$, folhas simples, 2,3-3,3 cm de comp. x 0,5-0,6 cm de larg., bicolor, lanceolada, base cuneada, ápice agudo, margem inteira, nervura primária e secundária proeminente em ambas as faces, face abaxial e adaxial com endurecimento do tipo pubescente. Inflorescência tirso, ausência de frutos. Esta espécie, de acordo com a Flora do Brasil é registro novo para o Distrito Federal.

Material examinado: Brasil, Distrito Federal, Chapada da Contagem, fértil, 06/X/1981. Kirkbride Jr., J. H. 4485.

Distribuição geográfica: Norte (Tocantins), Nordeste (Bahia), Centro-oeste (Goiás, Mato Grosso do Sul, Mato Grosso), Sudeste (Espírito Santo, Minas Gerais, São Paulo), Sul (Paraná).

Domínios fitogeográficos: Caatinga, Cerrado, Mata Atlântica.

Myrcia cordiifolia DC. Prodr. 3: 248. 1828. 
Subarbusto $60 \mathrm{~cm}$, folhas simples, 2,5-3 cm de comp. x 1-2,5 cm de larg., bicolor, lanceolada, base cuneada, ápice agudo, margem inteira, nervura primária e secundária proeminente em ambas as faces, face abaxial com endurecimento do tipo piloso e adaxial glabra. Fruto do tipo baga com endurecimento do tipo piloso, 0,3 $\mathrm{cm}$ de diâmetro, imaturo, cálice persistente com 5 lobos. Esta espécie, de acordo com a Flora do Brasil é registro novo para o Distrito Federal.

Material examinado: Brasil, Distrito Federal, encosta do morro da Canastra, fértil, 16/XII/1981. Kirkbrid, J. H. 4586.

Distribuição geográfica: Sudeste (Espírito Santo, Minas Gerais, Rio de Janeiro). Domínios fitogeográficos: Mata Atlântica.

Myrcia sellowiana O. Berg FI. Bras. 14(1): 197. 1857.

Árvore $6 \mathrm{~m}$, folhas simples, 3-14, $7 \mathrm{~cm}$ de comp. x 1,2-6,3 cm de larg., bicolor, lanceolada, base cuneada, ápice acuminado, margem inteira, nervura primária e secundária proeminente em ambas as faces, face abaxial com endurecimento do tipo piloso e adaxial glabra. Inflorescência panícula. Fruto do tipo baga com endurecimento do tipo pubescente, $0,3 \mathrm{~cm}$ de diâmetro, imaturo, cálice persistente com 5 lobos. Esta espécie, de acordo com a Flora do Brasil é registro novo para o Distrito Federal.

Material examinado: Brasil, Distrito Federal, fértil, 13/IX/1982. Kirkbride Jr., J. H. 4879.

Distribuição geográfica: Nordeste (Bahia), Sudeste (Espírito Santo).

Domínios fitogeográficos: Mata Atlântica.

Psidium myrsinoides O. Berg FI. Bras. 14(1): 384. 1857.

Nome vulgar: Araçá.

Árvore $6 \mathrm{~m}$, folhas simples, 0,7-8,4 cm de comp. $\times$ 0,5-7 cm de larg., bicolor, lanceolada, base cuneada, ápice agudo, margem inteira, nervura primária e secundária proeminente em ambas as faces, face abaxial com endurecimento do tipo piloso e adaxial glabra. Inflorescência em botão, tipo racemo, ausência de frutos.

Material examinado: Brasil, Distrito Federal, Jardim Botânico de Brasília, fértil, 16/X/2001. Soares e Silva, L. H. 1132. Distrito Federal, Reserva Ecológica do Gama, fértil, 14/XI/1999. Feretti, F. et al. 6. Maranhão, projeto geral de Balsas, lote 16, 11/XI/1996. Oliveira, R. C. e Silva, G. P. 136.

Distribuição geográfica: Norte (Tocantins), Nordeste (Bahia, Ceará, Maranhão), Centro-oeste (Distrito Federal, Goiás), Sudeste (Espírito Santo, Minas Gerais, Rio de Janeiro, São Paulo), Sul (Paraná, Rio Grande do Sul).

Domínios fitogeográficos: Caatinga, Mata Atlântica.

Eugenia stenosepala Kiaersk. Enum. Myrt. Bras. 155. 1893.

Árvore $4 \mathrm{~m}$, folhas simples, 4-6 cm de comp. x 5-6,5 cm de larg., bicolor, lanceolada, base cuneada, ápice agudo, margem inteira, nervura primária e secundária proeminente em ambas as faces, face abaxial e adaxial glabra. Ausência flores e frutos. Esta espécie, de acordo com a Flora do Brasil é registro novo para o Distrito Federal.

Material examinado: Brasil, Distrito Federal. APA do Cafuringa. 15/VII/1992. Proença, C.; Souza, M. L. 792.

Distribuição geográfica: Sudeste (Rio de Janeiro).

Domínios fitogeográficos: Mata Atlântica. 
Psidium guajava L. Sp. PI. 1: 470. 1753.

Nome vulgar: Goiabeira.

Árvore, folhas simples, 7,5-11,5 cm de comp. x 4-6 cm de larg., bicolor, oblonga, base obtusa, ápice arredondado, margem inteira, nervura primária e secundária proeminente em ambas as faces, face abaxial com endurecimento do tipo piloso e adaxial glabra. Ausência de flores e frutos.

Material examinado: Brasil, Maranhão, Comunidade Quilombola Olho D`água do Raposo, 05/VII/2009. Conceição, G. M.

Distribuição geográfica: Norte (Acre, Amazonas), Nordeste (Alagoas, Bahia, Ceará, Maranhão, Pernambuco, Piauí, Sergipe), Centro-oeste (Mato Grosso do Sul, Mato Grosso), Sudeste (Espírito Santo, Minas Gerais, Rio de Janeiro, São Paulo), Sul (Paraná, Rio Grande do Sul, Santa Catarina).

Domínios fitogeográficos: Amazônia, Caatinga, Cerrado, Mata Atlântica.

Eugenia dysenterica (Mart.) DC. Prodr. 3: 268. 1828.

Nome vulgar: Cagaita.

Árvore 1,50 m, folhas simples, 3-7, $5 \mathrm{~cm}$ de comp. $\times$ 2,6-4 cm de larg., bicolor, oblongo-lanceolada, base arredondada, ápice acuminado, margem inteira, nervura primária e secundária proeminente em ambas as faces, face abaxial e adaxial glabra. Ausência de flores e frutos.

Material examinado: Brasil, Maranhão, Mirador, Parque Estadual do Mirador. 08/IV/1998 13/XI/2007. Conceição, G. M. 98/25.

Distribuição geográfica: Norte (Tocantins), Nordeste (Bahia, Ceará, Maranhão, Pernambuco, Piauí), Centro-oeste (Distrito Federal, Goiás, Mato Grosso do Sul, Mato Grosso), Sudeste (Minas Gerais, São Paulo).

Domínios fitogeográficos: Caatinga, Cerrado, Mata Atlântica.

Eugenia dimorpha O. Berg FI. Bras. 14(1): 264. 1857.

Arbusto, folhas simples, 5-6, $5 \mathrm{~cm}$ de comp. x 3,6-3,8 cm de larg., bicolor, largoelíptico, base arredondada, ápice obtuso, margem inteira, nervura primária e secundária proeminente em ambas as faces, face abaxial e adaxial glabra. Inflorescência panícula, fruto do tipo baga com $0,3 \mathrm{~cm}$ de diâmetro, imaturo, cálice persistente truncado. Esta espécie, de acordo com a Flora do Brasil é registro novo para o Maranhão.

Material examinado: Brasil, Maranhão, APA do Inhamum, fértil. Conceição, G. M.

Distribuição geográfica: Sul (Rio Grande do Sul).

Domínios fitogeográficos: Mata Atlântica, Pampa.

Myrcia multiflora (Lam.) DC. Prodr. 3: 244. 1828.

Nome vulgar: Guamirim.

Arbusto, folhas simples, 1,5-4,5 cm de comp. x 0,6-2,5 cm de larg., bicolor, oblongolanceolada, base obtusa, ápice acuminado, margem inteira, nervura primária e secundária proeminente em ambas as faces, face abaxial com endurecimento do tipo incano e adaxial glabra. Fruto do tipo baga com 0,6 cm de diâmetro, imaturo, com endurecimento do tipo piloso, cálice persistente com 5 lobos. Esta espécie, de acordo com a Flora do Brasil é registro novo para o Maranhão.

Material examinado: Brasil, Maranhão, APA do Inhamum, fértil. Conceição, G. M. Distribuição geográfica: Norte (Acre, Amazonas, Pará), Nordeste (Bahia, Rio Grande do Norte), Centro-oeste (Distrito Federal, Goiás, Mato Grosso do Sul, Mato 
Grosso), Sudeste (Espírito Santo, Minas Gerais, Rio de Janeiro, São Paulo), Sul (Paraná, Rio Grande do Sul, Santa Catarina).

Domínios fitogeográficos: Amazônia, Caatinga, Cerrado, Mata Atlântica.

Myrciaria tenella (DC.) O. Berg Linnaea 27(2-3): 328. 1856

Nome vulgar: Cambuí.

Arbusto, folhas simples, 2,3-5 cm de comp. x 1,7-3,2 cm de larg., bicolor, oblongolanceolada, base cuneada, ápice agudo, margem inteira, nervura primária e secundária proeminente em ambas as faces, face adaxial com endurecimento do tipo piloso e abaxial glabra. Fruto do tipo baga com $0,5 \mathrm{~cm}$ de diâmetro, imaturo, cálice persistente com 4 lobos.

Material examinado: Brasil, Maranhão, APA do Inhamum, fértil. Conceição, G. M.

Distribuição geográfica: Norte (Pará), Nordeste (Bahia, Maranhão), Sudeste (Minas Gerais, Rio de Janeiro, São Paulo), Sul (Paraná, Rio Grande do Sul, Santa Catarina).

Domínios fitogeográficos: Amazônia, Caatinga, Cerrado, Mata Atlântica.

Psidium nutans O. Berg FI. Bras. 14(1): 394. 1857.

Nome vulgar: Goiaba-de-porco.

Arbusto 2,50 m, folhas simples, 2,3-10 cm de comp. x 1,2-3,7 cm de larg., bicolor, lanceolada, base cuneada, ápice agudo, margem inteira, nervura primária e secundária proeminente em ambas as faces, face abaxial e adaxial glabra. Fruto do tipo baga com endurecimento do tipo piloso, 2,3 cm de diâmetro, imaturo, cálice persistente com 5 lobos.

Material examinado: Brasil, Maranhão, Parque Estadual do Mirador, fértil, 19/IV/1998. Conceição, G. M. 234.

Distribuição geográfica: Norte (Tocantins), Nordeste (Bahia, Maranhão, Pernambuco, Piauí), Centro-oeste (Goiás, Mato Grosso do Sul, Mato Grosso), Sudeste (Minas Gerais).

Domínios fitogeográficos: Caatinga, Cerrado, Mata Atlântica.

Myrcia ochroides O. Berg FI. Bras., 14(1): 208, 1857.

Árvore $2 \mathrm{~m}$, folhas simples, 5-7 cm de comp. x 2,2-3 cm de larg., bicolor, lanceolada, base cuneada, ápice acuminado, margem inteira, nervura primária e secundária proeminente em ambas as faces, face abaxial com endurecimento do tipo velutino e adaxial glabra. Fruto do tipo baga com endurecimento do tipo piloso, $2,5 \mathrm{~cm}$ de diâmetro, imaturo, com endurecimento pubescente, cálice persistente com 5 lobos. Esta espécie, de acordo com a Flora do Brasil é registro novo para o Maranhão.

Material examinado: Brasil, Maranhão, projeto geral de Balsas, lote 16, fértil, 09/XI/1996. Oliveira, R. C. e Da Silva, G. P. 119.

Distribuição geográfica: Norte (Tocantins), Nordeste (Bahia, Piauí). Domínios fitogeográficos: Cerrado.

Myrcia goyazensis Cambess. FI. Bras. Merid. (quarto ed.) 2: 305. 1832.

Comentários da espécie: Arbusto $1 \mathrm{~m}$, folhas simples, $2,5-3 \mathrm{~cm}$ de comp. $\times 1-2,5$ $\mathrm{cm}$ de larg., bicolor, lanceolada, base cuneada, ápice agudo, margem inteira, nervura primária e secundária proeminente em ambas as faces, face abaxial com endurecimento do tipo piloso e adaxial glabra. Fruto do tipo baga com endurecimento do tipo piloso, $0,3 \mathrm{~cm}$ de diâmetro, imaturo, cálice persistente com 5 lobos. 
Material examinado: Brasil, Minas Gerais, Umuarama, fértil, 27/XI/2000. Proença, C. et al. 2305.

Distribuição geográfica: Norte (Tocantins), Centro-oeste (Distrito Federal, Goiás, Mato Grosso do Sul, Mato Grosso), Sudeste (Minas Gerais).

Domínios fitogeográficos: Cerrado.

\section{Psidium megalianum Cambess. \\ Nome vulgar: Araçá.}

Árvore $5 \mathrm{~m}$, folhas simples, 2,5-3 cm de comp. $\times 1-2,5 \mathrm{~cm}$ de larg., bicolor, lanceolada, base cuneada, ápice agudo, margem inteira, nervura primária e secundária proeminente em ambas as faces, face abaxial com endurecimento do tipo piloso e adaxial glabra. Inflorescência em botões, tipo panícula, ausência de frutos.

Material examinado: Brasil, Maranhão, Parque Estadual do Mirador, fértil, 08/XI/1998. Conceição, G. M. 393.

Distribuição geográfica: Maranhão

Domínios fitogeográficos: Cerrado.

Myrcia canescens O. Berg. FI. Bras. 14(1): 206. 1857.

Arbusto $1 \mathrm{~m}$, folhas simples, $1,4-5,5 \mathrm{~cm}$ de comp. $\times$ 0,6-2,2 $\mathrm{cm}$ de larg., bicolor, oblongo-lanceolada, base obtusa, ápice acuminado, margem inteira, nervura primária e secundária proeminente em ambas as faces, face abaxial e adaxial glabra. Inflorescência panícula, fruto do tipo baga com endurecimento do tipo pubescente, $0,3 \mathrm{~cm}$ de diâmetro, imaturo, cálice persistente com 5 lobos. Esta espécie, de acordo com a Flora do Brasil é registro novo para o Maranhão.

Material examinado: Brasil, Maranhão, Parque Estadual do Mirador, fértil, 20/VIII/1998. Conceição, G. M.. 255.

Distribuição geográfica: Norte (Tocantins), Nordeste (Bahia), Centro-oeste (Goiás, Mato Grosso do Sul, Mato Grosso), Sudeste (Minas Gerais, São Paulo).

Domínios fitogeográficos: Cerrado.

Myrcia lancea (O.Berg) Mattos. Arq. Bot. Estado São Paulo n.s., f.m., 4: 62. 1966. Arbusto $2 \mathrm{~m}$, folhas simples, $1-8 \mathrm{~cm}$ de comp. $\times$ 0,7-2,3 $\mathrm{cm}$ de larg., bicolor, lanceolada, base cuneada, ápice agudo, margem inteira, nervura primária e secundária proeminente em ambas as faces, face adaxial com endurecimento do tipo piloso e abaxial glabra. Inflorescência panícula.

Material examinado: Brasil, Maranhão, Parque Estadual do Mirador, fértil, 06/XI/1998. Conceição, G. M. 335.

Distribuição geográfica: Norte (Amazonas, Pará), Nordeste (Alagoas, Bahia, Ceará, Maranhão, Paraíba, Pernambuco, Piauí, Sergipe), Centro-oeste (Distrito Federal, Goiás, Mato Grosso do Sul, Mato Grosso), Sudeste (Espírito Santo, Minas Gerais, Rio de Janeiro, São Paulo), Sul (Paraná).

Domínios fitogeográficos: Amazônia, Caatinga, Cerrado, Mata Atlântica. Myrcia rufipes DC. Prodr. 3: 247. 1828.

Arbusto $1 \mathrm{~m}$, folhas simples, $2-3,5 \mathrm{~cm}$ de comp. $\times 1-2,0 \mathrm{~cm}$ de larg., unicolor, lanceolada, base cuneada, ápice agudo, margem inteira, nervura primária e secundária proeminente em ambas as faces, face adaxial e adaxial com endurecimento do tipo pubescente. Inflorescência em glomero, ausência de frutos. Esta espécie, de acordo com a Flora do Brasil é registro novo para o Maranhão. 
Material examinado: Brasil, Maranhão, Parque Estadual do Mirador, fértil, 08/XI/1998. Conceição. G. M. 394.

Distribuição geográfica: Nordeste (Alagoas, Bahia), Centro-oeste (Goiás), Sudeste (Espírito Santo, Minas Gerais, São Paulo).

Domínios fitogeográficos: Caatinga, Cerrado, Mata Atlântica.

Eugenia ayacuchae Steyerm. Fieldiana, Bot. 28: 1012. 1957.

Arbusto, folhas simples, 5,2-6,4 cm de comp. x 2,5-3,1 cm de larg., bicolor, oblongolanceolada, base obtusa, ápice agudo, margem inteira, nervura primária e secundária proeminente em ambas as faces, face adaxial e abaxial glabra. Inflorescência em botões, tipo glomero, ausência de frutos. Esta espécie, de acordo com a Flora do Brasil é registro novo para o Maranhão.

Material examinado: Brasil, Maranhão, Parque Estadual do Mirador, fértil, 07/XI/1998. Conceição, G. M. 380.

Distribuição geográfica: Nordeste (Bahia), Sudeste (Espírito Santo).

Domínios fitogeográficos: Mata Atlântica.

Myrcia rorida (O. Berg) Kiaersk. Enum. Myrt. Bras. 79. 1893.

Arbusto 1,8 $\mathrm{m}$, folhas simples, $3-8 \mathrm{~cm}$ de comp. $\times 2-3,5 \mathrm{~cm}$ de larg., bicolor, lanceolada, base cuneada, ápice agudo, margem inteira, nervura primária e secundária proeminente em ambas as faces, face adaxial e abaxial glabra. Fruto do tipo baga com $1 \mathrm{~cm}$ de diâmetro, imaturo, cálice persistente com 5 lobos.

Material examinado: Brasil, Minas Gerais, São Romão, fértil, 16/XII/2000. Gomes, B. M. et al. 129.

Distribuição geográfica: Norte (Acre, Amazonas, Amapá, Pará), Nordeste (Alagoas, Bahia, Ceará, Pernambuco, Rio Grande do Norte), Centrooeste (Goiás, Mato Grosso do Sul, Mato Grosso), Sudeste (Espírito Santo, Minas Gerais, Rio de Janeiro, São Paulo), Sul (Rio Grande do Sul, Santa Catarina).

Domínios fitogeográficos: Amazônia, Caatinga, Cerrado, Mata Atlântica.

Myrcia tomentosa (Aubl.) DC. Prodr. 3: 245. 1828.

Nome vulgar: Goiaba-brava.

Árvore $5 \mathrm{~m}$, folhas simples, 1,5-3,5 cm de comp. x 0,8-1,9 cm de larg., bicolor, oblongo-lanceolada, base obtusa, ápice acuminado, margem inteira, nervura primária e secundária proeminente em ambas as faces, face abaxial com endurecimento tipo pubescente e adaxial com endurecimento tipo piloso. Fruto do tipo baga com endurecimento do tipo piloso, $0,4 \mathrm{~cm}$ de diâmetro, imaturo, cálice persistente com 5 lobos.

Material examinado: Brasil, Maranhão, Parque Estadual do Mirador, fértil, 06/XI/1998. Conceição, G. M. 363. Minas Gerais, Garapuava, fértil, 26/XI/2000. Milhomens, L. C. et al. 44.

Distribuição geográfica: Norte (Amazonas, Pará), Nordeste (Alagoas, Bahia, Ceará, Maranhão, Paraíba, Pernambuco, Piauí, Sergipe), Centro-oeste (Distrito Federal, Goiás, Mato Grosso do Sul, Mato Grosso), Sudeste (Espírito Santo, Minas Gerais, Rio de Janeiro, São Paulo), Sul (Paraná).

Domínios fitogeográficos: Amazônia, Caatinga, Cerrado, Mata Atlântica.

Campomanesia sessiliflora (O. Berg) Mattos. Loefgrenia 26: 26. 1967.

Subarbusto, folhas simples, 3-6 cm de comp. x 0,8-2 cm de larg., bicolor, lanceolada, base cuneada, ápice agudo, margem inteira, nervura primária e secundária 
proeminente em ambas as faces, face abaxial com endurecimento tipo pubescente e adaxial com endurecimento tipo incano. Inflorescência em glomero, ausência de frutos.

Material examinado: Brasil, Minas Gerais, Umuarama, fértil, 27/XI/2000. Proença, C. et al. 2285.

Distribuição geográfica: Nordeste (Bahia), Centro-oeste (Goiás, Mato Grosso), Sudeste (Espírito Santo, Minas Gerais, São Paulo).

Domínios fitogeográficos: Caatinga, Cerrado, Mata Atlântica.

Eugenia persicifolia (O. Berg) Mattos. Fl. bras. 14(1): 226. 1857.

Arbusto $1 \mathrm{~m}$, folhas simples, 2,5-5 cm de comp. x 1-1,9 cm de larg., bicolor, lanceolada, base cuneada, ápice agudo, margem inteira, nervura primária e secundária proeminente em ambas as faces, face abaxial com endurecimento tipo piloso e adaxial com endurecimento tipo piloso. Inflorescência em botões, tipo glomero, ausência de frutos. Esta espécie, de acordo com a Flora do Brasil é registro novo para o Maranhão.

Material examinado: Brasil, Maranhão, Parque Estadual do Mirador, fértil. Conceição, G. M. 172.

Distribuição geográfica: Nordeste (Bahia), Sudeste (Espírito Santo).

Domínios fitogeográficos: Mata Atlântica.

Psidium pohlianum O. Berg. FI. Bras. 14(1): 390, 601. 1857.

Nome vulgar: Araçá.

Árvore 3,5 m, folhas simples, $2-6 \mathrm{~cm}$ de comp. $\times$ 1,2-3 cm de larg., bicolor, lanceolada, base cuneada, ápice agudo, margem inteira, nervura primária e secundária proeminente em ambas as faces, face abaxial e adaxial glabra. Fruto do tipo baga com $1,4 \mathrm{~cm}$ de diâmetro, imaturo, cálice persistente com 4 lobos. Esta espécie, de acordo com a Flora do Brasil é registro novo para o Maranhão.

Material examinado: Brasil, Maranhão, Parque Estadual do Mirador, fértil, 07/XI/1998. Conceição, G. M. 375.

Distribuição geográfica: Nordeste (Bahia), Norte (Tocantins), Centro-oeste (Distrito Federal Goiás, Mato Grosso, Mato Grosso do Sul), Sudeste (Minas Gerais,).

Domínios fitogeográficos: Cerrado.

Eugenia involucrata DC. Prodr. 3: 264. 1828.

Nome vulgar: Cereja-do-mato.

Arbusto $60 \mathrm{~cm}$, folhas simples, $1,3-8,5 \mathrm{~cm}$ de comp. $\times$ 0,8-2,5 $\mathrm{cm}$ de larg., bicolor, lanceolada, base cuneada, ápice agudo, margem inteira, nervura primária e secundária proeminente em ambas as faces, face abaxial e adaxial glabra. Fruto do tipo baga com 0,6 cm de diâmetro, imaturo, cálice persistente com 4 lobos. Esta espécie, de acordo com a Flora do Brasil é registro novo para o Distrito Federal.

Material examinado: Brasil, Distrito Federal, rebrota de área queimada, fértil, 14/X/2003. Paiva, V. F.; Milhomens, L. C. 181.

Distribuição geográfica: Sudeste (Espírito Santo, Minas Gerais, Rio de Janeiro, São Paulo), Sul (Paraná, Rio Grande do Sul, Santa Catarina).

Domínios fitogeográficos: Cerrado, Mata Atlântica.

Myrcia torta DC. Prodr. 3: 250. 1828.

Arbusto 0,8 cm, folhas simples, $1,4-5,5 \mathrm{~cm}$ de comp. x 0,6-2,2 $\mathrm{cm}$ de larg., bicolor, lanceolada, base cuneada, ápice arredondado, margem inteira, nervura primária em 
ambas as faces e nervura secundária sugada em ambas as faces, face abaxial e adaxial glabra. Inflorescência glomero, ausência de frutos. Esta espécie, de acordo com a Flora do Brasil é registro novo para o Distrito Federal.

Material examinado: Brasil, Distrito Federal, Jardim Botânico de Brasília, fértil, 16/X/2001. Soares e Silva, L. H. 1127.

Distribuição geográfica: Norte (Acre, Amazonas, Amapá, Pará), Nordeste (Alagoas, Bahia, Ceará, Pernambuco, Rio Grande do Norte), Centrooeste (Goiás, Mato Grosso do Sul, Mato Grosso), Sudeste (Espírito Santo, Minas Gerais, Rio de Janeiro, São Paulo), Sul (Rio Grande do Sul, Santa Catarina).

Domínios fitogeográficos: Amazônia, Caatinga, Cerrado, Mata Atlântica.

Myrcia rostrata DC. Prodr. 3: 255. 1828.

Arbusto $1 \mathrm{~m}$, folhas simples, 2,9-5,2 cm de comp. x 1,5-2,1 cm de larg., bicolor, lanceolada, base cuneada, ápice acuminado, margem inteira, nervura primária e secundária proeminente em ambas as faces, face abaxial e adaxial com endurecimento tipo piloso. Fruto do tipo baga $\mathrm{com} 0,3 \mathrm{~cm}$ de diâmetro, imaturo, cálice persistente com 4 lobos. Esta espécie, de acordo com a Flora do Brasil é registro novo para o Maranhão e o Distrito Federal.

Material examinado: Brasil, Maranhão, Parque Estadual do Mirador, fértil, 19/IV/1998. Conceição, G. M. 181. Distrito Federal, Parque Nacional de Brasília, fértil, 22/X/1990. Ramos, P. C. M. 147.

Distribuição geográfica: Norte (Acre, Amazonas, Amapá, Pará, Rondônia, Roraima, Tocantins), Nordeste (Alagoas, Bahia, Ceará, Paraíba, Pernambuco, Rio Grande do Norte, Sergipe), Centro-oeste (Goiás, Mato Grosso do Sul, Mato Grosso), Sudeste (Espírito Santo, Minas Gerais, Rio de Janeiro, São Paulo), Sul (Paraná, Rio Grande do Sul, Santa Catarina).

Domínios fitogeográficos: Amazônia, Caatinga, Cerrado, Mata Atlântica, Pantanal.

Gomidesia lindeniana O. Berg. Linnaea 29: 208. 1858.

Árvore $4 \mathrm{~m}$, folhas simples, $13-15,5 \mathrm{~cm}$ de comp. $\times 5-6 \mathrm{~cm}$ de larg., bicolor, lanceolada, base cuneada, ápice agudo, margem inteira, nervura primária e secundária proeminente em ambas as faces, face abaxial com endurecimento tipo pubescente e adaxial com endurecimento tipo piloso. Fruto do tipo baga com endurecimento do tipo piloso, $0,3 \mathrm{~cm}$ de diâmetro, imaturo, cálice persistente com 5 lobos.

Material examinado: Brasil, Distrito Federal, fértil, 24/VIII/1981. Kirkbrid, J. H. 4399. Distribuição geográfica: Nordeste (Bahia), Centro-oeste (Distrito Federal, Goiás), Sudeste (Minas Gerais, São Paulo).

Domínios fitogeográficos: Cerrado, Mata Atlântica.

\section{CONCLUSÃO}

Os espécimes da família Myrtaceae listados para a Coleção Botânica do CESC/UEMA, contabilizaram 44 espécies, distribuídos em 11 gêneros, totalizando 100 exemplares, dos quais, 64 espécimes foram registrados para o Maranhão. Os gêneros mais representativos foram: Eugenia L. com 37 espécimes, distribuídas em 15 espécies, Myrcia DC., com 32 espécimes, distribuídas em 14 espécies.

Das 44 espécies de Myrtaceae caracterizadas, foram registradas novas ocorrências para o Maranhão, Eugenia subterminalis, Eugenia speciosa, Eugenia uniflora, Eugenia dimorpha, Eugenia ayacuchae, Eugenia persicifolia, Mycia 
guianensis, Myrcia multiflora, Myrcia ochroides, Myrcia canescens, Myrcia rufipes, Myrcia rostrata, Campomanesia xanthocarpa, Psidium pohlianum e Myrceugenia cucullata. Para o Distrito Federal, Eugenia bracteata, Eugenia klotzschina, Eugenia stenosepala, Eugenia involucrata, Myrcia torta, Myrcia rostrata, Myrcia cordiifolia, Myrcia sellowiana, Campomanesia pubescens e Marlierea bipennis. Já para Goiás, Eugenia uruguayensis.

A família Myrtaceae tem grande importância econômica, ecológica e medicinal, a ocorrência de novos registros vem demonstrar que pouco se conhece sobre esta família, tendo-se a necessidade de se intensificar as pesquisas, pois os estudos ainda são escassos, principalmente para o Maranhão.

\section{REFERENCIAS}

ANGIOSPERM PHYLOGENY GROUP. An update 4. of the angiosperm phylogeny group classification for the orders and families of flowering plants: APG III. Bot J Lin Soc, v.161, n. 2, p. 105-21, out. 2009.

ARAGÃO J. G.; CONCEIÇÃO, G. M. Importância, diversidade e distribuição geográfica. 2007. 71f. Monografia (Graduação em Ciências com habilitação em Biologia) - Universidade Estadual do Maranhão, Caxias, 2007.

DIAS, C. N.; RODRIGUES, K. A. F.; RESPLANDES, S. M.; AGUIAR, L. R.; AMARAL, F. M. M.; MORAES, D. F. C. Caracterização farmacobotânica das folhas de Eugenia uniflora L. (MYRTACEAE) coletadas em São Luís-MA, Brasil. Rev. Ciênc. Saúde, Santa Catarina, v.14 n.2, p. 95-102, jul/dez. 2012.

GRESSLER, E. Polinização e dispersão de sementes em Myrtaceae do Brasil. Revista Brasileira de Botânica, São Paulo, v.29, n.4, p.509-530, out/dez. 2006.

LANDRUM, L. R.; KAWASAKI, M. L. The genera of Myrtaceae in Brazil. An illustrate synoptic treatment and identification keys. Brittonia, New York, v.49, n.4, p. 508536, dez. 1997.

LORENÇO, A. R. L.; BARBOSA, M. R. V. Myrtaceae em restingas no limite norte de distribuição de Mata Atlântica, Brasil. Rodriguésia, Rio de Janeiro, v.63, n.02, p.373393, set. 2012.

LORENZI, H.; BACHER, L.; LACERDA, M.; SARTORI, S. Frutas Brasileiras e Exóticas Cultivadas. Instituto Plantarum: Nova Odessa, 2006.

LORENZI, H.; MATOS, F. J. A. Plantas Medicinais no Brasil. Instituto Plantarum: Nova Odessa, 2002.

LORENZI, H.; SOUZA, H. M. Plantas Ornamentais no Brasil. 3o ed. Instituto Plantarum: Nova Odessa, 2001.

MYERS, N. MITTERMEIER, R. A.; MITTERMEIER, C. G. FONSECA G. A. B.; KENT, J. Biodiversity hotspots for conservation priorites. Nature, Reino Unido, v.403, p.853858, set/dez. 2000.

PIZZO, M. A. Padrão de deposição de sementes e sobrevivência de sementes e plântulas de duas espécies de Myrtaceae na Mata Atlântica. Revista Brasileira de Botânica, São Paulo, v. 26, p.3, p.371-377. Jul/set. 2003. 
SILVA-FILHO, J. F. Florística e fitossociologia da área de Proteção ambiental do Inhamum do município de Caxias e comparação com outras áreas do estado do Maranhão, Brasil. Monografia de Graduação. Universidade Estadual do Maranhão. Caxias-MA. 2006.

SILVA, J. M. C.; RYLANDS, A. B.; FONSECA, G. A. B. O. Destino das áreas de endemismo da Amazônia. Megadiversidade, Belo Horizonte, v.1, n.1, p.124-131, jul. 2005.

SOBRAL, M.; PROENÇA, C.; SOUZA, M.; MAZINE, F.; LUCAS, E. Myrtaceae in: Lista de Espécies da Flora do Brasil. Jardim Botânico do Rio de Janeiro, Rio de Janeiro, 10 de jan. 2014. Disponível em: <http://floradobrasil.jbrj.gov.br/>. Acesso em: 10 Jan. 2014.

SOARES-SILVA, L. H. A família Myrtaceae - subtribos: Myrciinae e Eugeniinae na bacia hidrográfica do Rio Tibagi, estado do Paraná, Brasil. 2000. 462f. Tese. (Doutorado em Biologia Vegetal) - Universidade Estadual de Campinas, São Paulo, 2000.

SOBRAL, M.; LUCAS, E.; LANDRUM, L.; SOARES-SILVA, L. Myrtaceae in: STHEMAN, J.; FORZZA, R. C.; SALINO, A.; SOBRAL, M.; COSTA, D. P.; KAMINO, L. H. Y. Plantas da Floresta Atlântica. Instituto de Pesquisas Jardim Botânico do Rio de Janeiro, Rio de Janeiro, 2009. Disponível em: http://www.jbrj.gov.br/publica/livros_pdf/plantas_floresta_atlantica.pdf. Acesso em: 07 de dez. 2013.

SOUSA, Z. J. C. Ocorrência de Myrtaceae no Cerrado da Área de Proteção Ambiental Municipal Inhamum, Caxias, Maranhão, Brasil. Monografia 2011. $38 f$. (Graduação em Ciências com habilitação em Biologia) - Universidade Estadual do Maranhão, Caxias, 2011.

SOUZA, V. C.; LORENZI, H. Botânica Sistemática: Guia ilustrado para identificação das famílias de Angiospermas da flora brasileira, baseado em APG II. $2^{\circ}$ ed. Instituto Plantarum: Nova Odessa, 2008. 


\section{A}

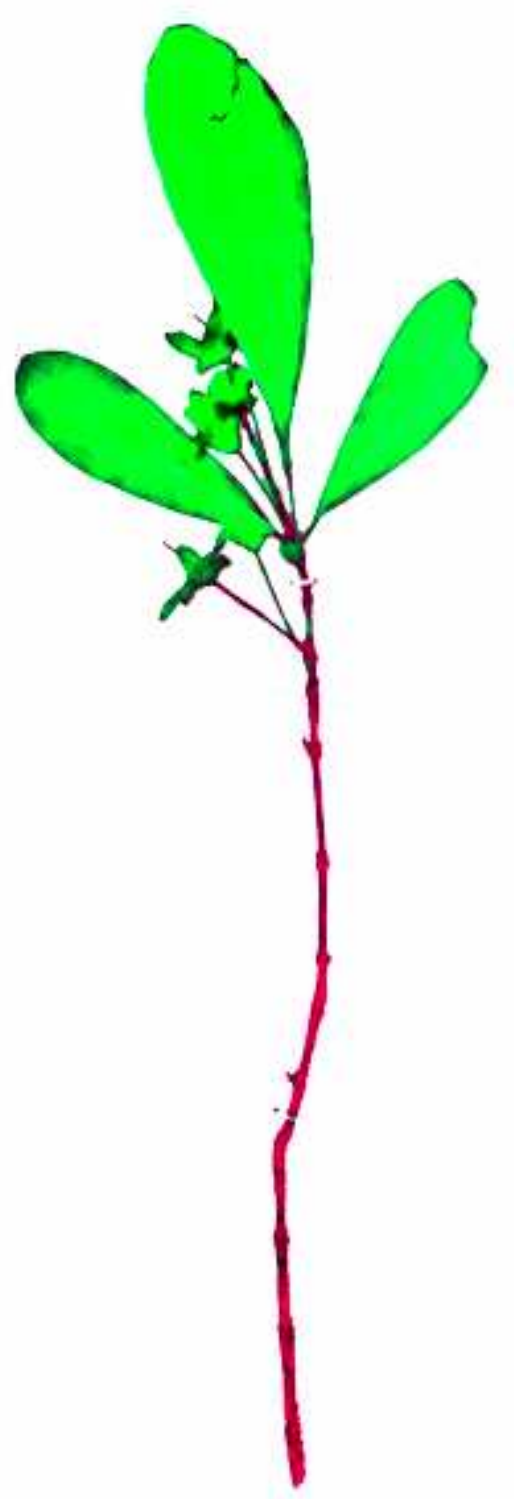

Figura: A - Eugenia bracteata Vell.

Foto: Morais, L.M.F.

Fonte: Coleção Botânica do CESC/UEMA. 


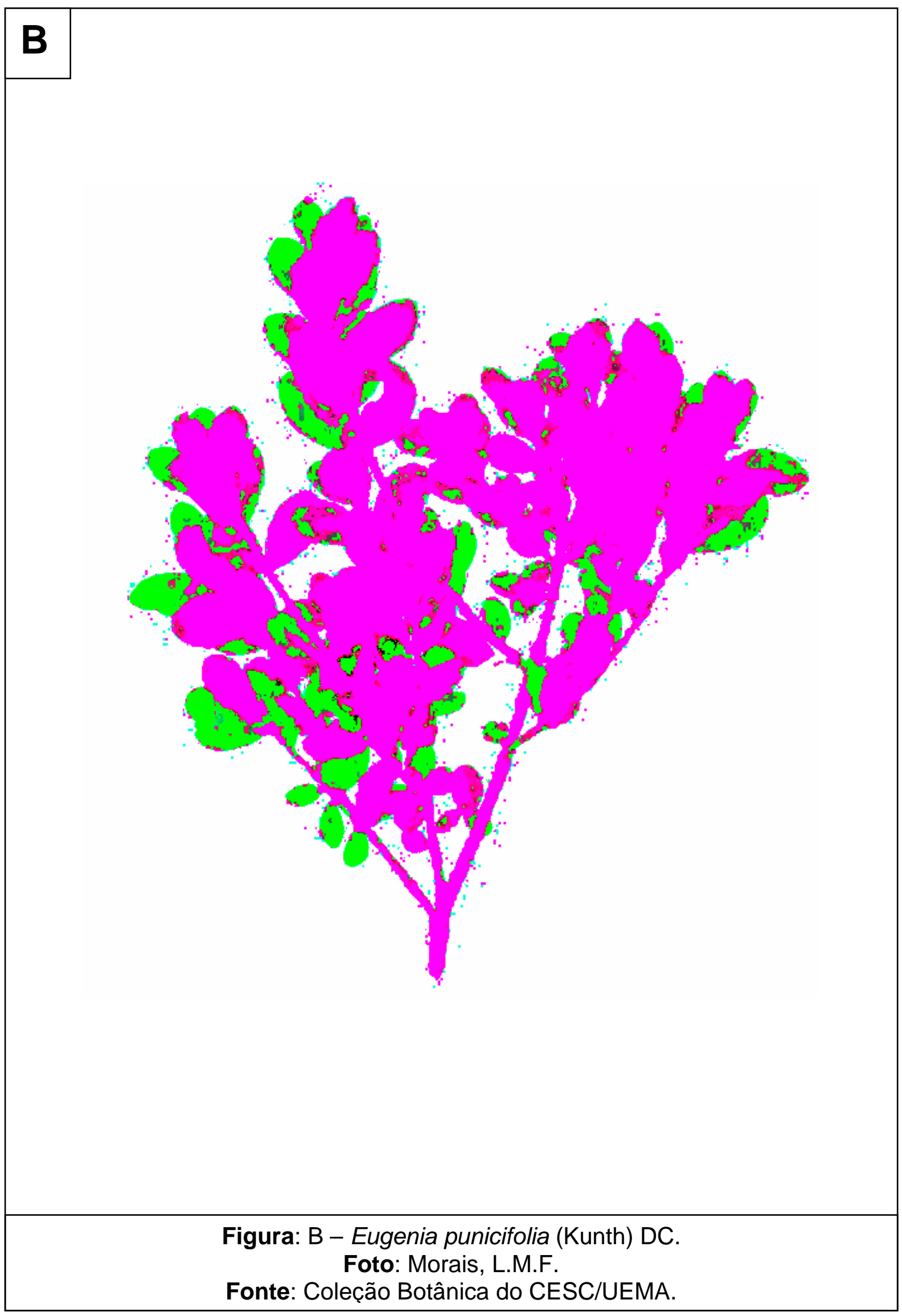




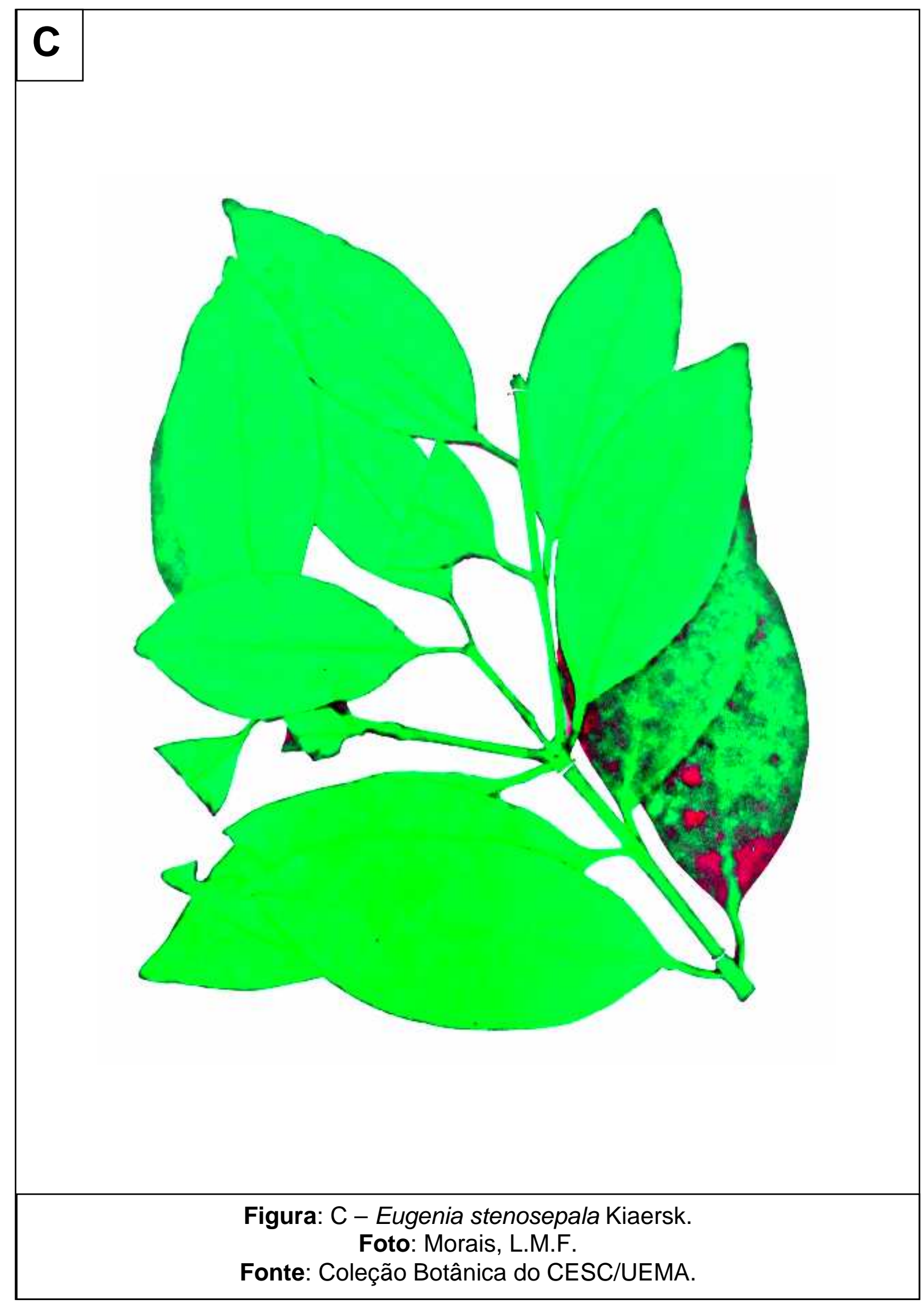




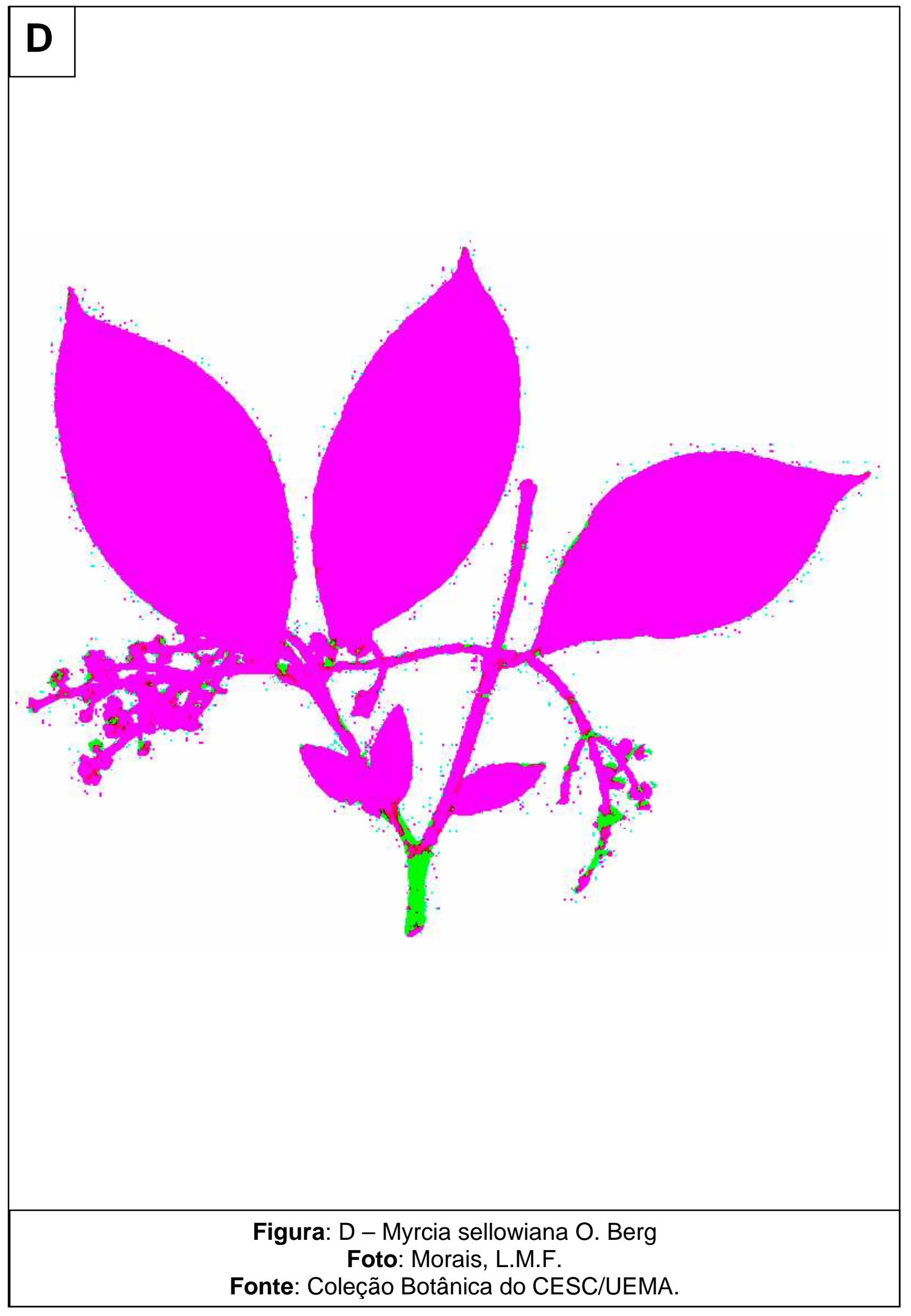




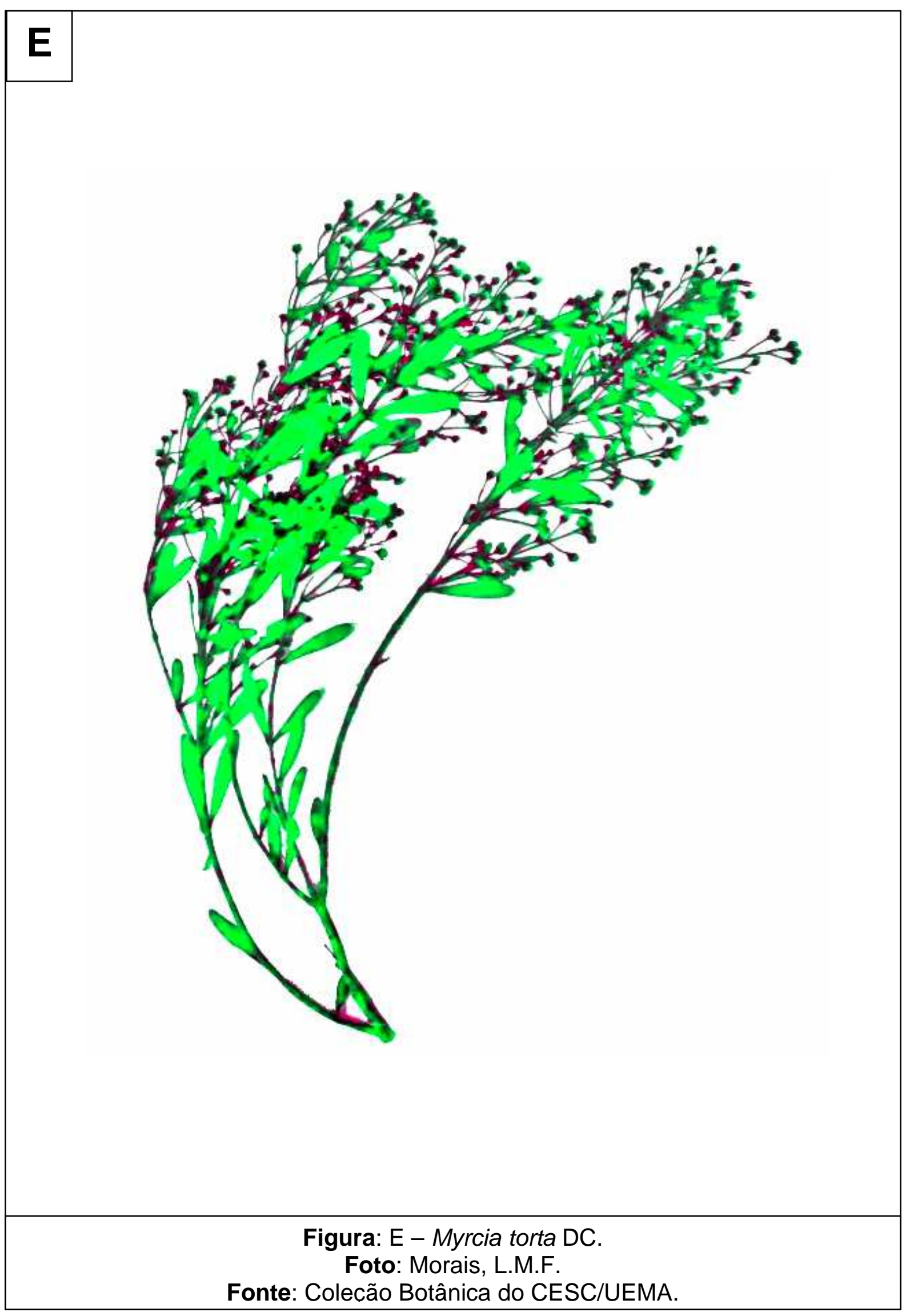




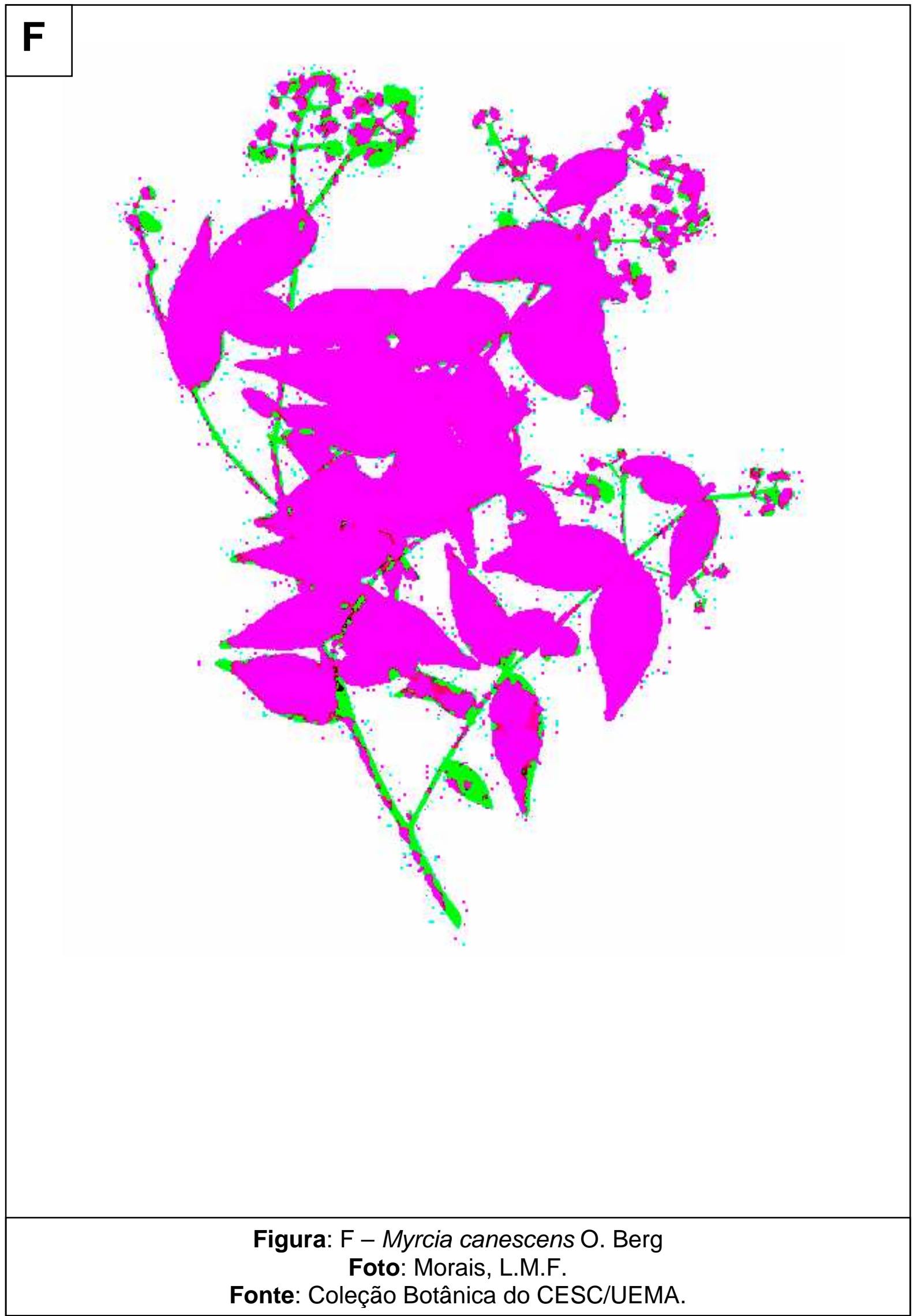




\section{G}

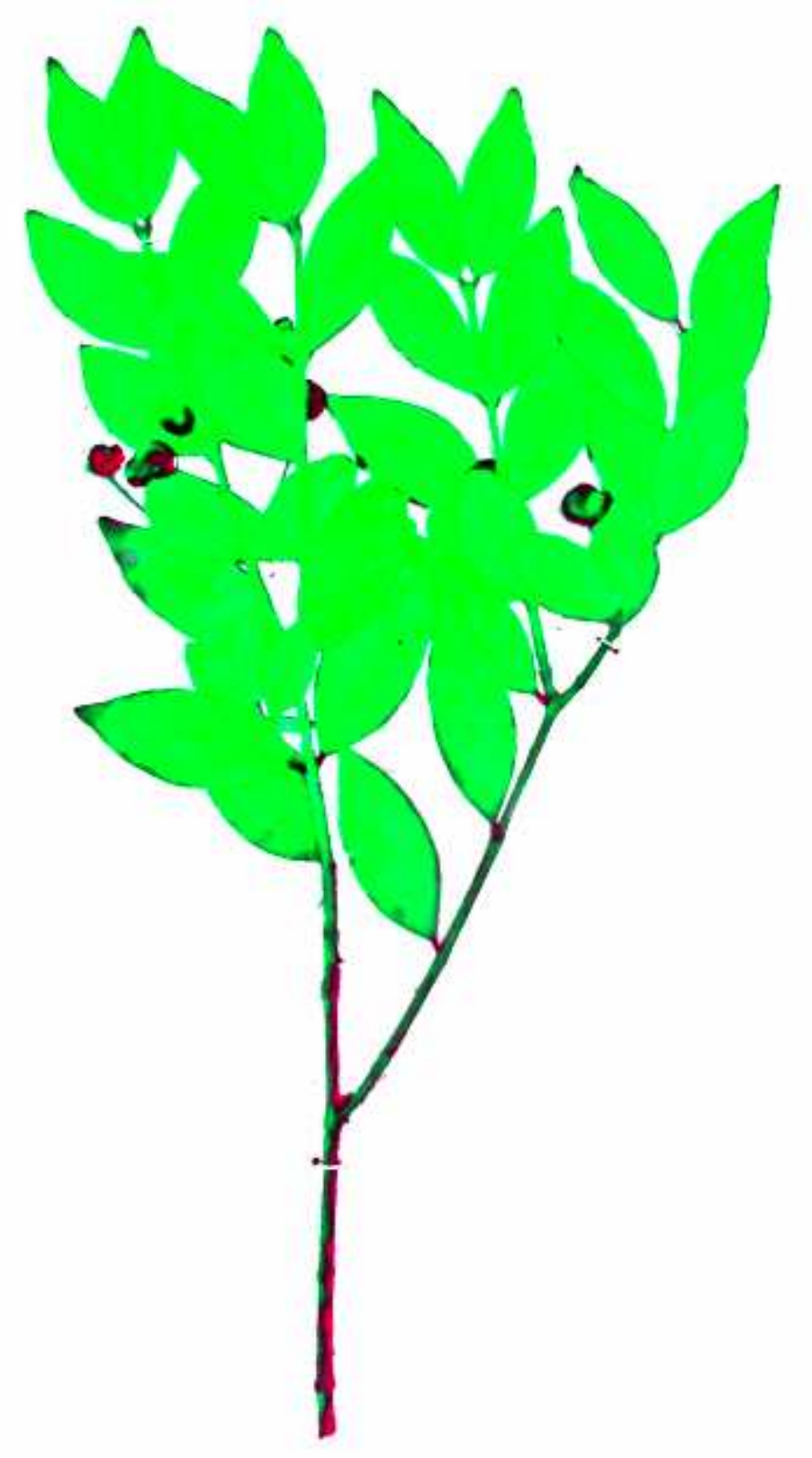

Figura: G - Blepharocalyx salicifolius (Kunth) O. Berg Foto: Morais, L.M.F. Fonte: Coleção Botânica do CESC/UEMA. 


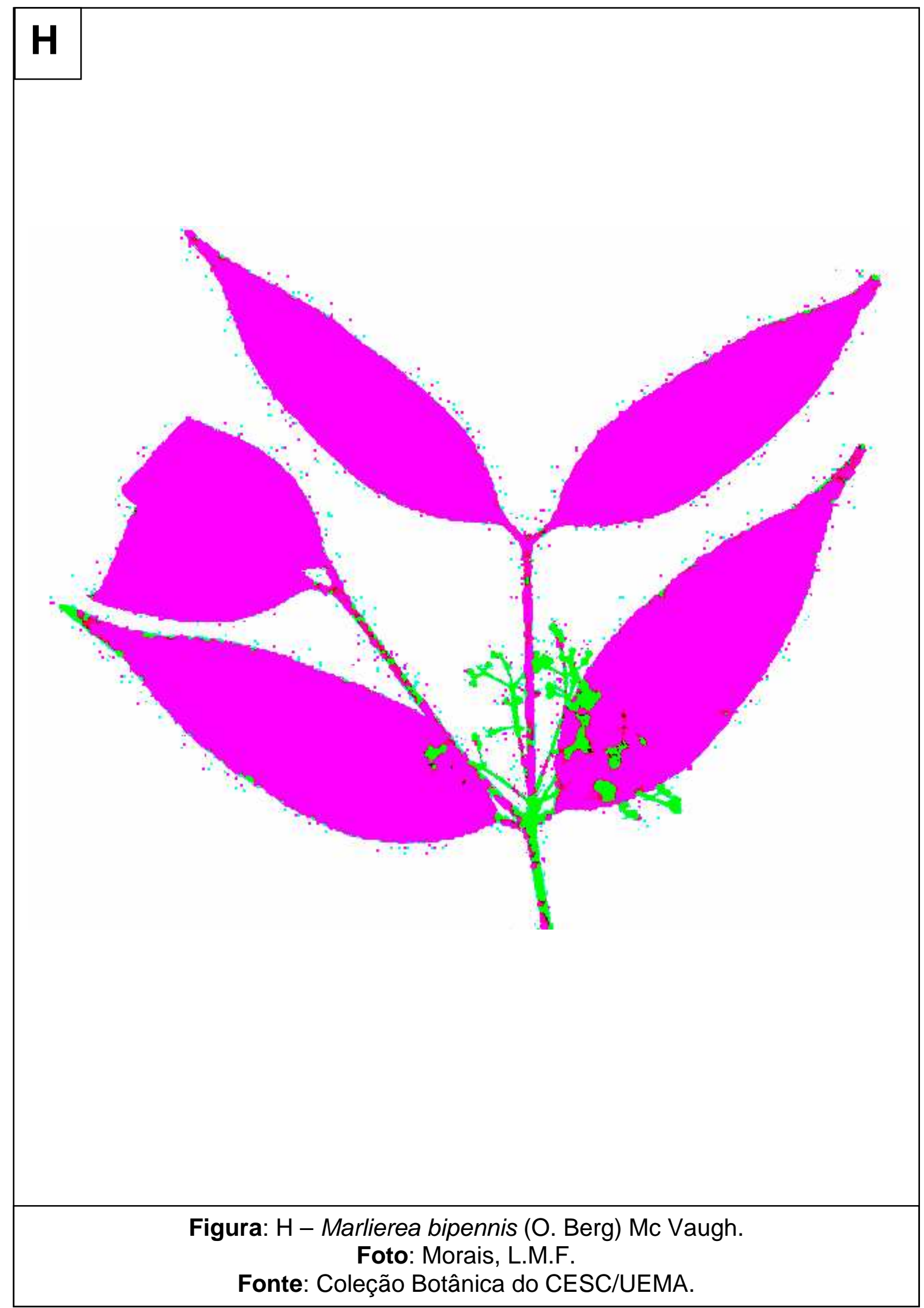

